\title{
Genetic Dissection of Functional Contributions of Specific Potassium Channel Subunits in Habituation of an Escape Circuit in Drosophila
}

\author{
Jeff E. Engel and Chun-Fang Wu \\ Department of Biological Sciences, University of lowa, lowa City, lowa 52242
}

Potassium channels have been implicated in central roles in activity-dependent neural plasticity. The giant fiber escape pathway of Drosophila has been established as a model for analyzing habituation and its modification by memory mutations in an identified circuit. Several genes in Drosophila encoding $\mathrm{K}^{+}$channel subunits have been characterized, permitting examination of the contributions of specific channel subunits to simple conditioning in an identified circuit that is amenable to genetic analysis. Our results show that mutations altering each of four $\mathrm{K}^{+}$channel subunits ( $\mathrm{S} h$, slo, eag, and $\mathrm{Hk}$ ) have distinct effects on habituation at least as strong as those of dunce and rutabaga, memory mutants with defective cAMP metabolism (Engel and Wu, 1996). Habituation, spontaneous recovery, and dishabituation of the electrically stimulated longlatency giant fiber pathway response were shown in each mutant type. Mutations of Sh (voltage-gated) and slo $\left(\mathrm{Ca}^{2+}\right.$-gated) subunits enhanced and slowed habituation, respectively. However, mutations of eag and $H k$ subunits, which confer $\mathrm{K}^{+}$current modulation, had even more extreme phenotypes, again enhancing and slowing habituation, respectively. In double mutants, Sh mutations moderated the strong phenotypes of eag and $H k$, suggesting that their modulatory functions are best expressed in the presence of intact Sh subunits. Nonactivitydependent responses (refractory period and latency) at two stages of the circuit were altered only in some mutants and do not account for modifications of habituation. Furthermore, failures of the long-latency response during habituation, which normally occur in labile connections in the brain, could be induced in the thoracic circuit stage in Hk mutants. Our work indicates that different $\mathrm{K}^{+}$channel subunits play distinct roles in activity-dependent neural plasticity and thus can be incorporated along with second messenger "memory" loci to enrich the genetic analysis of learning and memory.

Key words: habituation; learning and memory; giant fiber escape response circuit; Drosophila; insects; invertebrates; $\mathrm{K}^{+}$; potassium channels; $\alpha$ subunit; $\beta$ subunit; Shaker; Sh; slowpoke; slo; ether à go-go; eag; Hyperkinetic; Hk
Experience-dependent neural plasticity implies the modification of synaptic strength or neural firing properties by activity. $\mathrm{K}^{+}$ channels are likely to be crucial, both as regulators of neural activity and as targets of modulation leading to lasting changes in synaptic efficacy (Rudy, 1988; Alkon, 1990; Hille, 1992; Klein, 1995; Byrne and Kandel, 1996). However, roles of different channel subunits are difficult to dissect using conventional physiological and pharmacological approaches, in which effects are rarely limited to one channel type. Therefore there is value to a genetic approach that allows identified channels to be mutated in intact animals, linking behavioral alterations to cellular or molecular defects.

Several genes identified by hyperexcitable phenotypes (i.e., leg shaking) have been shown to encode $\mathrm{K}^{+}$channel subunits (Kaplan and Trout, 1969; Hall, 1982; Wu and Ganetzky, 1992) of different families that contribute to a variety of $\mathrm{K}^{+}$channels in Drosophila and other animals including vertebrates (Jan and Jan, 1990; Rehm and Tempel, 1991; Salkoff et al., 1992; Chouinard et al., 1995; Ganetzky et al., 1995; Baro et al., 1997). Furthermore, mutations that modify ion channels can affect behavioral plastic-

\footnotetext{
Received June 30, 1997; revised Jan. 5, 1998; accepted Jan. 6, 1998.

This work was supported by National Institutes of Health Grants NS18500 and NS26528 to C.-F.W. We thank Xianjin Xie for technical assistance and Drs. D. Baro and R. Harris-Warrick for comments on this manuscript.

Correspondence should be addressed to Dr. Jeff E. Engel, Section of Neurobiology and Behavior, Cornell University, Seeley Mudd Hall, Ithaca, NY 14853.

Copyright (C) 1998 Society for Neuroscience $0270-6474 / 98 / 182254-14 \$ 05.00 / 0$
}

ity, e.g., in courtship (Sh,eag) (Cowan and Siegel, 1984; Griffith et al., 1994) and classical olfactory conditioning (Sh) (Cowan and Siegel, 1986). However, the functional contributions of these subunits to channels in neural circuits are not well understood.

Three such genes encode $\alpha$ (pore-forming) subunits of multimeric $\mathrm{K}^{+}$channels with different properties. Shaker $(S h)$ channels are voltage-gated (Salkoff and Wyman, 1981; Wu and Haugland, 1985; Iverson et al., 1988; Timpe et al., 1988), whereas slowpoke (slo) channels are activated by cytoplasmic $\mathrm{Ca}^{2+}$ (Komatsu et al., 1990; Atkinson et al., 1991). Both could regulate neuronal excitability and synaptic transmission (Jan et al., 1977; Tanouye et al., 1981; Ganetzky and Wu, 1982; Elkins et al., 1986; Gho and Ganetzky, 1992). The ether à go-go (eag) subunit seems to coassemble into channels with other subunit types, and eag mutations affect several $\mathrm{K}^{+}$currents, including those mediated by Sh and slo channels (Zhong and Wu, 1991b, 1993b; Chen et al., 1996). Sequence analysis and physiological results suggest that the eag subunit is a target for channel modulation by phosphorylation and cyclic nucleotide binding (Warmke et al., 1991; Brüggemann et al., 1993; Zhong and Wu, 1993b; Griffith et al., 1994). Hyperkinetic (Hk) encodes a $\beta$ (auxiliary) subunit (Chouinard et al., 1995) that associates with heterologously expressed $S h$ channels to confer modulation (Rettig et al., 1994; Chouinard et al., 1995; Rhodes et al., 1995), and $H k$ mutations alter the amplitude and kinetics of $S h$-type currents, especially in near-threshold voltages, in Drosophila muscle (Wang and Wu, 1996) and cultured neurons (Yao and Wu, 1995). 


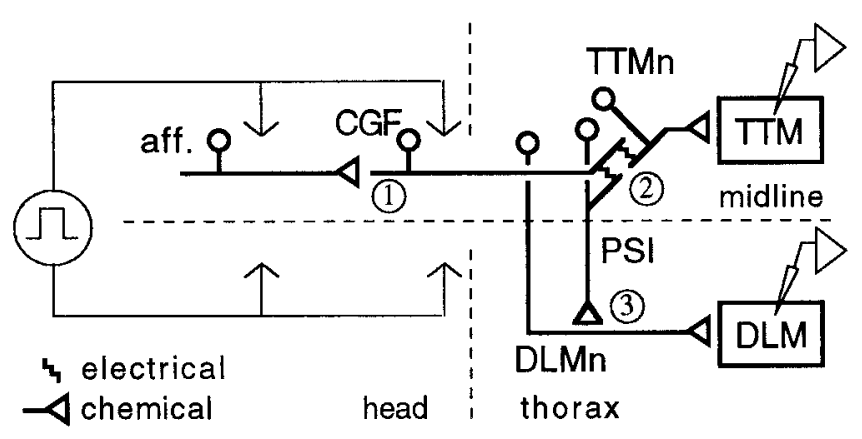

Figure 1. Schematic of the giant fiber pathway, showing one half of the bilateral circuit. Visual and other afferent pathways (here represented as a single neuron, aff.) feed to the $C G F$, which descends to activate TTM (jump) and $D L M$ (wing depressor) branches in the thorax. Low-voltage stimulation, passed between electrodes in the eyes, activates afferent pathways (aff.) to trigger a long-latency response that can habituate. Higher-voltage stimulation directly activates the $C G F$ to evoke a nonhabituating short-latency response. Numbered sites $(1,2,3)$ are referred to in the Results. $D L M n 5$ is shown, because recordings were usually from its target muscle fiber, DLM a. For anatomy, see King and Wyman (1980), Strausfeld and Bassemir (1983), and Ikeda and Koenig (1988); for functional connectivity, see references in Engel and Wu $(1992,1996)$ and Lin and Nash (1996). aff., Afferent pathway; $C G F$, cervical giant fiber; $D L M$, dorsal longitudinal muscle; DLMn, DLM motoneuron; PSI, peripherally synapsing interneuron; TTM, tergotrochanteral muscle; TTMn, TTM motoneuron.

Differences in the action and modulation of Sh, eag, slo, and $H k$ subunits suggest that they could play distinct functional roles in neural plasticity. However, differential expression and alternative RNA splicing of these genes in different excitable tissues (Schwarz et al., 1988, 1990; Stocker et al., 1990; Tseng-Crank et al., 1991; Becker et al., 1995; Mottes and Iverson, 1995), with the potential for heteromeric subunit combinations (Haugland and Wu, 1990; Isacoff et al., 1990; McCormick et al., 1990; Ruppersberg et al., 1990; Wu and Chen, 1995; Chen et al., 1996), raise the question of how a diversity of $\mathrm{K}^{+}$channel types regulates different circuit components. Such functional complexity could be dissected via the use of mutations to analyze plasticity in a well defined circuit.

The study of mechanisms of neural plasticity has been facilitated by simple conditioning paradigms such as habituation (e.g., Thompson and Spencer, 1966; Klein et al., 1980; Fitzgerald et al., 1990; Krasne and Teshiba, 1995). However, only recently has the genetic analysis of habituation been applied to an identified neural circuit in the fly in which molecular and behavioral phenotypes can be linked to physiology (Engel and Wu, 1996). The giant fiber escape pathway mediates a visually evoked jump-andflight escape response (Levine and Tracey, 1973; Tanouye and Wyman, 1980; Wyman et al., 1984). Different intensities of electrical stimulation, passed between electrodes in the eyes, can be used to activate afferent elements in the brain (long-latency response) or to bypass them and trigger the thoracic stage (shortlatency response) (Fig. 1), enabling the analysis of distinct circuit components with different response properties (Elkins and Ganetzky, 1990; Trimarchi and Schneiderman, 1993; Engel and Wu, 1996; Lin and Nash, 1996). We have demonstrated that the long-latency response shows characteristic parameters of habituation (Thompson and Spencer, 1966) and have used the memory mutations rut and dnc (Dudai, 1988; Tully, 1991; Davis, 1996) to show that perturbing cAMP metabolism affects habituation in this circuit (Engel and Wu, 1996), consistent with their effects on behavioral plasticity (e.g., Corfas and Dudai, 1989). We report here that mutations of identified $\mathrm{K}^{+}$channel subunits induce specific and distinct effects on habituation in the giant fiber circuit of the fly, to an extent as extreme as rut and $d n c$.

\section{MATERIALS AND METHODS}

Controls were Canton-Special (CS) flies $(n=41)$. Mutant stocks were as follows: for Shaker, $\operatorname{Sh}^{K S 133}(n=15), y$ cho f $\operatorname{Sh}^{\text {rKO120 }}(n=11)$, and $S h^{5}$ $(n=6)(\mathrm{Wu}$ and Haugland, 1985); for slowpoke, slo st $(n=17)$ (Elkins et al., 1986) and slo ${ }^{98}(n=2)$ (Komatsu et al., 1990); for ether à go-go, eag $^{1}(n=11)$ and eag $^{4 p m}(n=5)$ (Ganetzky and $\left.\mathrm{Wu}, 1983\right)$; and for Hyperkinetic, $H k^{1}(n=5)$ and the viable deletion $H k^{I E 18}(n=6)$ (Wang and Wu, 1996). Combinations were eag ${ }^{I} \operatorname{Sh}^{K S 133}(n=10)$ and eag ${ }^{1}$ $S^{r K O 120}(n=9)$ (Ganetzky and Wu, 1983) and $H^{1} f \operatorname{Sh}^{r K O 120}(n=5)$, $H k^{1} f S^{5}(n=5)$, and $H^{1}{ }^{1}$ eag $^{1} \operatorname{Sh}^{K S 133}(n=5)$ (Yao and Wu, 1995). Values of $n$ refer to the primary data set displayed in the Results (see Figs. 2, 3, 6, 7, Table 1); results for mutant alleles of each gene did not differ and were pooled, except that $S h^{K S 133}$ is contrasted with $S h^{r K O 120}$ and $S h^{5}$ (see Figs. 3, 6A, Table 1). Viable genetic markers of eye color [chocolate (cho), garnet $(g)$, and scarlet $(s t)]$, body color [yellow $(y)]$, and bristle morphology [forked $(f)$ ] are described by Lindsley and Zimm (1992). Ether-induced shaking behavior was present in these stocks as reported previously, and in eag $S h$ double mutants, the characteristic occurrence of flies with wings held downward and an indented notum was also noted (Engel and Wu, 1992).

Physiological methods were described in Engel and Wu (1996). Highand low-voltage pulses from electrodes in the eyes were used to trigger the cervical giant fiber (CGF) or afferent inputs to the CGF in the brain (Fig. 1). For the short-latency response, stimuli were $\sim 2 \mathrm{~V}$ above threshold; for the long-latency response, stimuli were set $0.2-0.4 \mathrm{~V}$ below the threshold for shorter latency responses (Engel and Wu, 1996), except that stimulus voltage was reduced further for some trials as noted (see Figs. $5,10)$. Responses were recorded from a tergotrochanteral muscle (TTM) (leg extensor) and a fiber of the contralateral dorsal longitudinal muscle (DLM) (wing depressor) (Fig. 1). DLM fiber a was most commonly recorded; previous work indicates that ipsilateral DLM fibers respond and fail together in habituation of the long-latency response (Engel and $\mathrm{Wu}, 1996)$.

For habituation trials, stimulation was given at $5 \mathrm{~Hz}$, found previously to induce habituation within tens to hundreds of stimuli in a variety of genotypes (Engel and Wu, 1996), except for some trials as noted (see Figs. 5, 10). Habituation was indicated by a criterion of five consecutive failures of the DLM flight muscle response (Engel and Wu, 1996), and trials were terminated after five consecutive failures to test recovery or after 1000 stimuli $(200 \mathrm{sec})$ if criterion was not obtained first. Air puffs (Engel and $\mathrm{Wu}, 1996)$ were given immediately after five consecutive failures to test dishabituation. For statistical analyses, data for stimulito-failure criterion (see Fig. 3) and refractory periods (see Fig. 8) were log-transformed to improve normality (Engel and Wu, 1996).

\section{RESULTS}

\section{Habituation in single mutants}

We demonstrated previously six of the parameters of habituation of Thompson and Spencer (1966) for the long-latency giant fiber response, including frequency dependence, spontaneous recovery, faster rehabituation, habituation beyond zero response, dishabituation by air puff or light flash, and habituation of dishabituation (Engel and Wu, 1996). A seventh parameter, stronger habituation with weaker stimulation, is described below. To characterize habituation in several mutants of four gene loci, this work focused on the most essential parameter, loss of the response, at a standard stimulus strength and frequency (see Materials and Methods). Recovery and dishabituation were also examined to demonstrate reversibility. Long-latency giant fiber responses to electrical stimulation and habituation of the response were obtained in flies of every genotype.

Mutations affecting different channel subunits led to profound differences in the rate of habituation (Fig. 2, Table 1) and the time required to reach a criterion level of habituation (i.e., five con- 

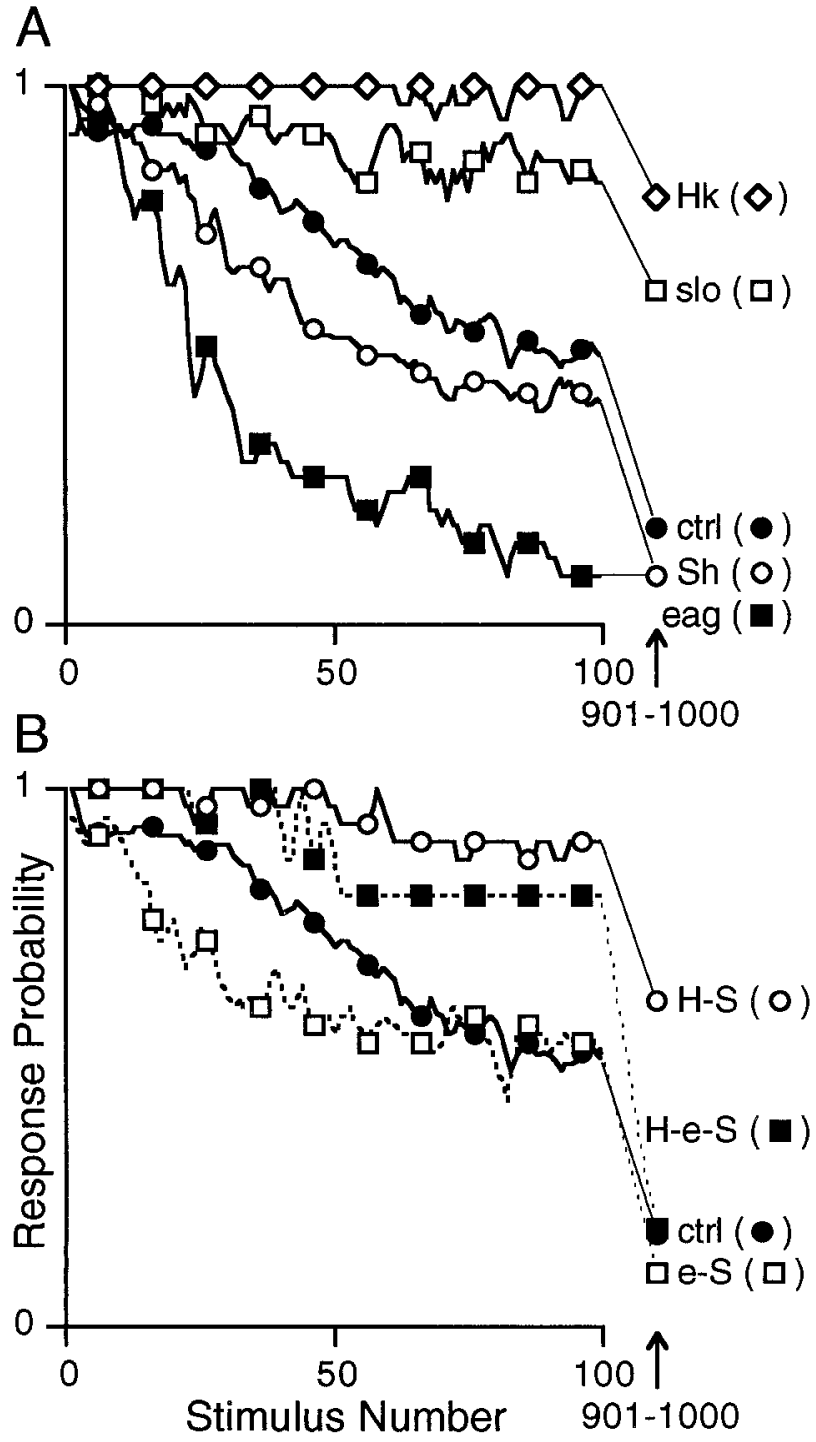

Figure 2. Habituation of the long-latency response in control and mutant flies. $A, B$, Electrical stimuli were given at $5 \mathrm{~Hz}$ until five consecutive failures or 1000 stimuli. DLM muscle responses for different alleles of each genotype were combined (see Materials and Methods for alleles used) and smoothed (three-point running average) for the first 100 stimuli, with the final 100 stimuli averaged to a single point (901-1000). Line dashing and symbols set on lines are to aid in distinguishing curves. Sample sizes are indicated below [see Fig. 3 (with $S h$ alleles combined)]. ctrl, Control; H-S, Hk Sh; e-S, eag Sh;H-e-S,Hk eag Sh; alleles of each mutant type are combined (see also Figs. 4, 8, 9; Materials and Methods).

secutive failures; Fig. 3). Different mutant alleles of each gene produced consistent results, except that two alleles of $S h$ that modify channel function differed from an allele that eliminates function (see below). Therefore, alleles have been combined in figures and tables unless indicated otherwise. Similarities between mutant alleles of a gene locus indicate the phenotypes are attributable to those loci rather than unidentified variability in other parts of the genome.

$S h$ and slo encode subunits with homologous structure, with the major distinction that $S h$ subunits are voltage-gated whereas slo subunits require cytosolic $\mathrm{Ca}^{2+}$ for activation $(\mathrm{Wu}$ and Ganetzky, 1992). Two slo mutations, slo ${ }^{1}$ and $s l o^{98}$, markedly reduced the rate of habituation (Fig. 2, Table 1) and the time to
Table 1. Response likelihood for stimuli 69-78

\begin{tabular}{lllr}
\multirow{2}{*}{$\begin{array}{l}\text { Mutant } \\
\text { class }\end{array}$} & \multicolumn{2}{l}{ Response Likelihood } \\
\cline { 2 - 4 } mean & SEM & $n$ \\
\hline Control & 0.56 & 0.073 & 41 \\
Hk & $0.98^{* *}$ & 0.018 & 11 \\
slo & $0.84^{*}$ & 0.067 & 19 \\
Sh & 0.65 & 0.122 & 15 \\
$S^{123}+S h^{5}$ & $0.25^{*}$ & 0.101 & 17 \\
eag & $0.15^{* *}$ & 0.082 & 16 \\
Hk Sh & $0.89^{*}$ & 0.099 & 10 \\
Hk eag Sh & 0.80 & 0.200 & 5 \\
eag ${ }^{1}$ Sh & 0.73 & 0.127 & 10 \\
eag & Sh & 0.163 & 36 \\
rut & 0.36 & 0.066 & 32 \\
dnc & 0.76 & 0.076 & 21 \\
dnc rut & $0.26^{* * *}$ & 0.080 &
\end{tabular}

In controls, response likelihood crossed 0.5 at stimulus 74 (compare Fig. 2). Response likelihood over the 10 stimuli was calculated for each fly, then averaged for each mutant class, and compared with controls (two-tailed $t$ test; ${ }^{*} p<0.05 ;{ }^{*} p<$ $0.01 ; * * * p<0.001$ ). Except for $S h$ and eag Sh, different alleles (listed in Materials and Methods) gave similar results and are combined (same trials shown in Fig. 3). Results for learning mutants $r u t$ and $d n c$ were calculated from previous trials (Engel and $\mathrm{Wu}, 1996)$.

reach five-failure criterion (Fig. 3), so that many slo mutant flies did not achieve five consecutive failures within the trial length limit of 1000 stimuli. slo ${ }^{1}$ and slo $^{98}$ may be amorphic (null), because both alleles eliminate a $\mathrm{Ca}^{2+}$-activated $\mathrm{K}^{+}$current in muscle (Elkins et al., 1986; Komatsu et al., 1990). In contrast, Sh mutants habituated more rapidly than did controls (Fig. 2, Table 1), but there were interesting differences between alleles. $S h^{5}$ and $S h^{r K O 120}$, which express functional but altered subunits, led to earlier habituation (Fig. 3, Table 1). The $S h^{5}$ mutation, in an exon common to all $S h$ transcripts (Gautam and Tanouye, 1990; Lichtinghagen et al., 1990), alters channel-gating kinetics and voltage sensitivity (Salkoff and Wyman, 1981; Wu and Haugland, 1985); the $S^{r K O 120}$ lesion site is not known but may affect specific splicing variants because its phenotype is far more extreme in neurons than in muscle (Wu and Haugland, 1985; Wu and Ganetzky, 1992). $S h^{K S 133}$, a missense mutation that affects the pore-forming region of all transcripts (Lichtinghagen et al., 1990), is an antimorph (Haugland and $\mathrm{Wu}, 1990)$ that eliminates a transient $\mathrm{K}^{+}$current, $I_{A}$, in muscle (Salkoff and Wyman, 1981; $\mathrm{Wu}$ and Haugland, 1985). Surprisingly, its effects on habituation were less extreme than were those of $S h^{5}$ and $S h^{r K O 120}$ (Fig. 3, Table 1).

Mutations of the two subunits implicated in channel modulation, eag and $H k$, had even stronger effects on habituation than did $S h$ and slo, respectively. $\mathrm{eag}^{1}$ and $e a g^{4 \mathrm{pm}}$ increased the rate of habituation (Fig. 2, Table 1) and reduced the number of stimuli to attain five consecutive failures (Fig. 3). $H k^{1}$ and the amorphic deletion $H k^{I E 18}$ both dramatically reduced the rate of habituation (Fig. 2, Table 1) and delayed attainment of five consecutive failures (Fig. 3), so that the majority of $H k$ mutants did not attain this criterion within 1000 stimuli. It should be noted that habituation was assessed according to DLM muscle responses (Engel and $\mathrm{Wu}, 1996)$, but in many $H k$ flies, the TTM muscle continued to respond after the DLM pathway failed (an otherwise rare phenomenon, described below). In this respect, the phenotype of $H k$ mutants could be even more extreme than is indicated by these plots (Figs. 2, 3). 


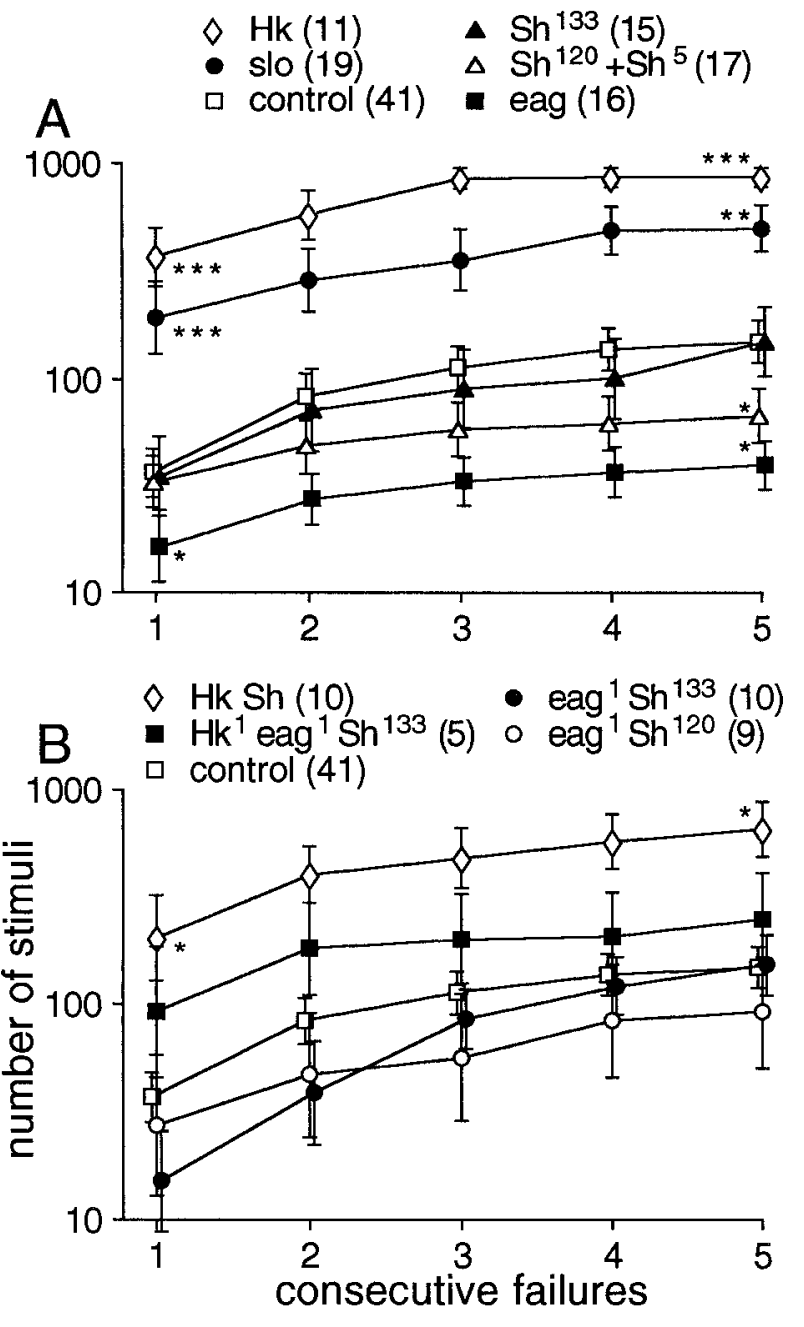

Figure 3. Number of stimuli (means \pm SEM) to attain one to five consecutive failures in control and mutant flies (same trials shown in Fig. 2). $A, B$, Results for each genotype were log-transformed (see Materials and Methods) before computing statistics. Except for $S h$ and eag $S h$, different alleles gave similar results and are combined (see also Figs. 6, 7, Table 1). Numbers of stimuli to first failure (i.e., consecutive failures $=1$ ) and five failures were tested against controls using a two-tailed $t$ test $\left({ }^{*} p<0.05 ;{ }^{* *} p<0.01 ; * * * p<0.001\right)$. Sample sizes are indicated in parentheses. $\mathrm{SH}^{133}, \mathrm{Sh}^{\mathrm{KS} 133} ; \mathrm{Sh}^{120}, \mathrm{Sh}^{r K O 120}$; see Materials and Methods for other mutant alleles.

\section{Dishabituation, spontaneous recovery, and failure patterns}

It is important to consider whether the conditioning induced in these mutants is habituation as defined previously in this system (Engel and Wu, 1996). As defined previously, habituation can be localized to a portion of the circuit in the head (Fig. 1) because DLM and TTM muscle responses failed in synchrony (an exception is described below), and the pathway in the thorax can respond at frequencies well above the $5 \mathrm{~Hz}$ used to induce habituation (Engel and Wu, 1992; see Fig. 8B for comparison). Response latencies were only slightly altered in mutants (see below), and there were no abrupt changes in latency during habituation that could have indicated a novel activity-dependent circuit response.

Moreover, two critical characteristics of habituation, spontaneous recovery and dishabituation induced by a novel stimulus (air puff), were observed in flies of all genotypes. Figure 4 shows spontaneous recovery after $30 \mathrm{sec}$ of rest after habituation by 5 $\mathrm{Hz}$ stimuli. eag, $\mathrm{Sh}$, and slo mutants recovered at least as fully as did controls. $H k$ flies are not represented in Figure 4 because they did not readily reach the five-failure habituation criterion at $5 \mathrm{~Hz}$, but $H k$ animals did recover from habituation when tested with increased stimulus frequencies in order to attain habituation (see below).

Figure 5 shows examples of dishabituation in each of the mutant types. To demonstrate dishabituation in slowly habituating $H k$ and slo mutants, we could use a higher stimulation frequency or a lower stimulus voltage to induce habituation (Fig. 5, see Fig. 10). The latter approach takes advantage of a negative relationship between stimulus intensity and the strength of habituation (Thompson and Spencer, 1966), a parameter of habituation that was not reported previously in this system (Engel and Wu, 1996).

The mutant genotypes may be distinguished further by examining the clustering of response failures. Again, eag and $H k$ produced the most pronounced deviations from controls. Figure $6 A$ plots the cumulative frequency of switches between responses and failures. The slope of a curve indicates both the frequency of failures and the degree of clustering (longer strings of successes or failures lead to fewer switches). The curve for eag was similar to that for $S h^{r K O 120}$ and $S h^{5}$ during the first 100 stimuli but was steeper than that for $S h^{K S 133}$, reflecting a greater number of failure strings. After approximately stimulus 90, the eag curve flattened abruptly because of the termination of faster-habituating trials at five-failure criterion (Fig. 6 $A$, inset).

The pattern of failures also differed between slo and $H k$ mutants (Fig. 6A), even though both showed diminished habituation (Figs. 2, 3). Failure onset was delayed in slo mutants; the earliest failure (in 19 trials) occurred at the 16 th stimulus (Fig. 6A). After failure onset, response-and-failure switching was as frequent as in controls until approximately stimulus 175 , when the rate diminished indicating that the remaining subset of slo animals (i.e., trials not yet terminated; Fig. $6 A$, inset) switched less frequently. In contrast, failure onset was much later in $H k$ trials, no earlier than stimulus 62 (in 11 trials), and the frequency of switching (slope in Fig. 6A) never attained the level seen in controls.

Figure $6 B$ shows the frequency of strings of consecutive failures in the first 100 stimuli, grouped by string length. The first bar in each histogram in Figure $6 B$ [no failures $(n f)$ ] indicates the proportion of trials without a single failure in 100 stimuli. The last bar $(5+)$ indicates the proportion of trials in which a string of five or more failures occurred (equal to or more than five because trials were terminated after five consecutive failures). The most notable result in Figure $6 B$ is that the rankings for those two categories are consistent with the rates of habituation indicated in Figures 2 and 3; for $n f, H k>$ slo $>$ controls $>S h>e a g$, and for $5+, H k<$ slo $<$ controls $\leq S h<e a g$. Distribution patterns of one to four failure strings were less markedly different between genotypes. Slower habituation in slo is attributable to shorter failure strings, because the average number of failures in 100 stimuli was similar to that in controls and $S h$ (Fig. 6B, failures/trial). In contrast, $H k$ failed much less than did slo because of late failure onset (compare Fig. 6A). eag mutants showed the greatest failure frequency, even though the true frequency is underestimated because most eag animals habituated in under 100 stimuli (Fig. $6 A$, inset). 


\section{Habituation in double mutants}

Of the channel subunit genes studied, eag mutants showed the most extreme increase in strength of habituation, whereas $H k$

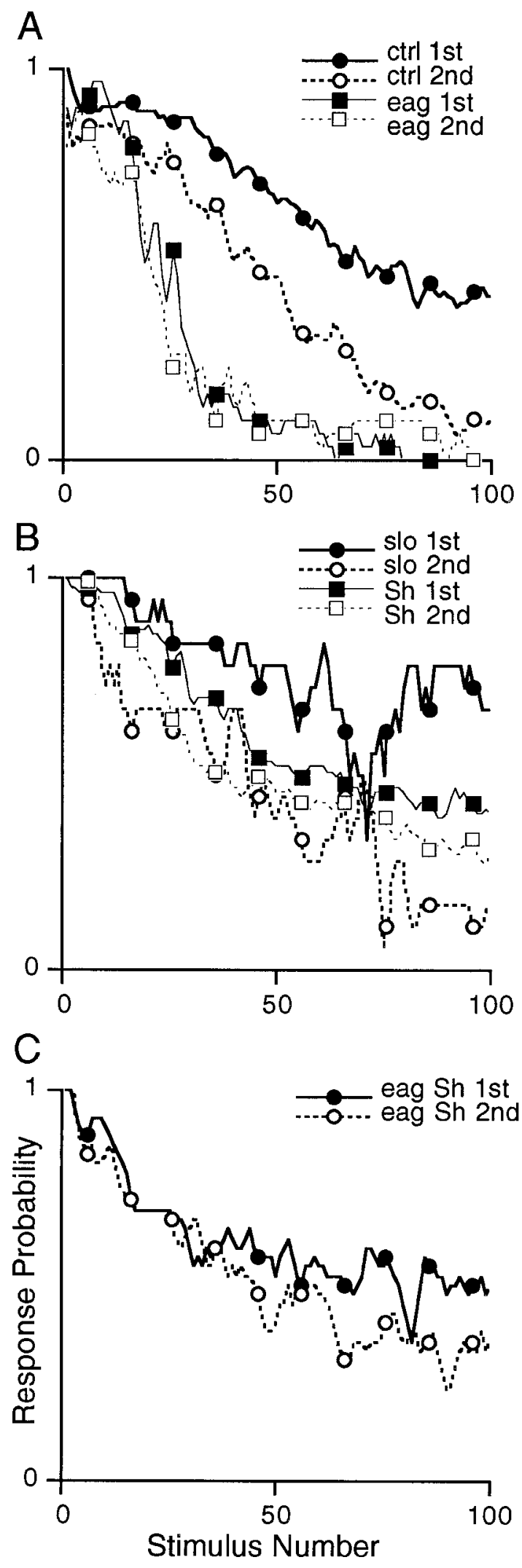

mutants showed the most extreme decrease (Figs. 2, 3, 6, Table 1). There is strong physiological evidence (reviewed in the introductory remarks) that both $e a g$ and $H k$ subunits can interact with $S h$ channels. Therefore, double- and triple-mutant combinations were examined to determine how these interactions contribute to habituation. eag and $S h$ mutations generally interact to produce phenotypes more extreme than that produced by either mutation alone for characters including motoneuron excitability, terminal branching and synaptic transmission at neuromuscular junctions, leg shaking, novel wing position, and defective flight (Ganetzky and Wu, 1983; Budnik et al., 1990; Engel and Wu, 1992). This is consistent with the finding that in muscle, eag contributes to several K ${ }^{+}$currents besides the $S h I_{A}$ (Zhong and Wu, 1993b; Wu and Chen, 1995). Therefore, it was surprising that rates of habituation in eag $S h$ double mutants were no more extreme than the rates in either $S h$ or eag alone (Figs. 2, 3, Table 1). Failures began early in eag $S h$ double mutants (Fig. $7 A$ ), as in eag alone, but isolated failures (string length $=1$ ) were common (Fig. 7B). Spontaneous recovery from habituation in eag $S h$ double mutants is shown in Figure 4.

In contrast to eag and $S h, H k$ and $S h$ mutations generally do not interact to produce more extreme phenotypes than produced by Sh alone for characters including neuromuscular synaptic facilitation and aberrant neuronal spiking (Stern and Ganetzky, 1989; Yao and Wu, 1995; W.-D. Yao and C.-F. Wu, unpublished observations), and in both muscle and neurons, $H k$ has only been shown to affect the $S h I_{A}$ current (Yao and Wu, 1995; Wang and $\mathrm{Wu}, 1996)$. Yet, habituation in $H k S h$ double mutants was markedly retarded, as in $H k$ mutants, rather than more rapid as in $S h$ (Figs. 2, 3, Table 1). The strong effect of $H k$ was apparent even in $H k^{1}$ eag $^{1} S^{K S 133}$ triple mutants, which habituated more slowly than did controls, unlike eag, Sh, or eag Sh (Figs. 2, 3). In Hk Sh and $H k$ eag $S h$ mutants, failure onset was delayed compared with Sh or eag $S h$ (Fig. $7 A$ ), yet rates of response-and-failure switching (Fig. $7 A$ ) were more normal than in $H k$ alone.

Double- and triple-mutant results indicate that the modification of $S h$ subunits alone has less impact on habituation than does altering $H k$ or eag subunits in the presence of functional $S h$ subunits. Unlike the previously studied excitability phenotypes listed above, habituation is an activity-dependent process. Apparently, $H k$ and eag mutations affect conditioning processes more severely than does $S h$, even though $S h$ affects nonactivitydependent parameters of the giant fiber response, including the latency and refractory period as described below.

\section{Resting properties: refractory period and latency}

Refractory period and response latency are temporal characteristics on a millisecond scale that might influence the process of habituation, a type of activity-dependent conditioning lasting seconds or longer. These processes could be mediated by over-

$\leftarrow$

Figure 4. Recovery from habituation in control and mutant flies. $A-C$, After habituation to five-failure criterion (1st, filled symbols and solid lines), flies were allowed to recover for $30 \mathrm{sec}$ and given a second stimulus bout (2nd, open symbols and dashed lines). Two aspects of recovery to be noted are the response likelihood in the initial stimuli of the second bout and the rate of subsequent habituation. $H k$ mutants are not included in this paradigm because of the infrequency of five consecutive failures with $5 \mathrm{~Hz}$ stimulation. Results were combined and smoothed as described for Figure 2. Symbols set on lines are to aid in distinguishing curves. Trials are a subset of those shown in Figure 2. Sample sizes are control $(\mathrm{ctrl})=35$; eag $=10 ;$ slo $=6 ; S h=25$; and eag $S h=14$. 
lapping mechanisms at overlapping sites in the circuit. In fact, we found that alterations in refractory period and response latency in $\mathrm{K}^{+}$channel mutants do not account for their effects on habituation. To analyze response properties at two stages of the giant fiber pathway, low-voltage stimuli were used to trigger the longlatency response that begins in labile-afferent pathways in the brain where habituation is mediated (Engel and Wu, 1996), whereas stronger stimuli were given to bypass the afferent stage (see Materials and Methods) and trigger a short-latency response in the thoracic portion of the circuit (Fig. 1).

Refractory periods of the long-latency response tended to be shorter than normal in all $\mathrm{K}^{+}$channel mutants examined except in eag $S h$ double mutants (Fig. $8 A$ ), which were normal. This indicates that habituation rate is not coupled to refractory period in this system, because the two parameters are not altered in the same pattern across genotypes. A similar lack of correlation was shown with cAMP-metabolic mutations of dunce and rutabaga (Engel and Wu, 1996). Short-latency response refractory periods, mediated by the nonlabile thoracic pathway, were affected quite differently in the same mutants (Fig. $8 B$ ); they were not shortened in any $\mathrm{K}^{+}$channel mutants but were prolonged in eag $S h$ (cf. Engel and $\mathrm{Wu}, 1992), H k$, and $H k$ Sh mutants.

Response latencies were also affected differently in cephalic and thoracic stages of the pathway (Fig. 9). The long-latency response was delayed slightly in $S h$ and eag $S h$ mutants. Sh, eag $S h$, and slo mutations induced small but statistically significant delays in short-latency TTM responses, whereas $H k$ and eag mutations led to earlier short-latency DLM responses. The small scale of these differences indicates that the giant fiber pathway is still functional (cf. Baird et al., 1990) and weighs against the recruitment of potential collateral pathways in slo and $H k$ mutants (see below). Although latency increased gradually during habituation (Engel and Wu, 1996), sudden increments were not observed. The most notable feature of these results, however, is that the pattern of nonactivity-dependent properties of nerve conduction and synaptic transmission in the circuit, including marked effects on the long-latency response refractory period, do not correlate with habituation phenotypes. The lack of a simple relationship among habituation, response latency, and refractory period in $\mathrm{K}^{+}$ channel mutants implies that activity-dependent plasticity could involve multiple cellular mechanisms at different sites in the circuit, influenced by $\mathrm{K}^{+}$currents, that shape efficacy in axonal conduction and synaptic transmission.

\section{Shift of long-latency response failure site in $\mathrm{K}^{+}$ channel mutants}

Habituation of the long-latency response is characterized by synchronous failures of DLM and TTM responses (Fig. 5) (Engel and $\mathrm{Wu}, 1996$ ), indicating that failures occur in the brain (Fig. 1). However, in some animals of certain genotypes, the DLM branch of the circuit failed more readily than did the TTM branch. This pattern was seen most often in flies with $H k$ mutations (Engel, 1995) or Hk combinations (Fig. 10), less frequently in slo (Fig. 5) and eag $S h$ (data not shown) mutants, and rarely in other mutants or controls (even in individual flies that habituated unusually slowly, approaching the level of $H k$ or slo mutants). These independent DLM failures probably occur after the circuit has bifurcated in the thorax (Fig. 1), and consistent with this, a similar pattern of DLM failures coupled with TTM responses could be observed when short-latency responses were induced by increasing stimulus intensity (Engel, 1995).

This pattern could indicate a shift in the site of failures from normally labile synapses in the head (e.g., site 1 in Fig. 1) to electrical or cholinergic synapses of the DLM branch in the thorax (sites 2 or 3 ). One plausible explanation could be the recruitment of normally silent afferents in the brain leading to stronger transmission of the signal to the giant fiber (i.e., at site 1). Decreasing stimulus intensity or interstimulus intervals typically promotes habituation (Thompson and Spencer, 1966), and to extend the above scenario, extra afferent inputs activated in mutants could fail under these stimulus conditions. Indeed, after the two muscle responses had become decoupled, it was sometimes possible to induce the "typical" pattern of synchronous DLM and TTM failures either by decreasing stimulus intensity to just above the long-latency response threshold ( $s o^{1}$ in Fig. 5, $H k^{1}$ eag $^{1} S^{K S 133}$ in Fig. 10) or by increasing the rate of stimulation ( $\mathrm{Hk}^{1}$ rKO120 in Fig. 10).

Conversely, drastically reduced TTM failures in $H k, H k S h$, and $H k$ eag $S h$ mutants could indicate recruitment of parallel inputs to the thoracic TTM branch. Although the exact site of modification in the pathway awaits further investigation, the long-latency TTM response is clearly strengthened by $H k$ mutations even more than is the long-latency DLM response. The typical pattern of synchronized muscle responses could still occur in these mutants (Figs. 5, 10), which indicates that the normal site of habituation in the brain is labile in these flies as well. The apparent shift in the site of failures under certain stimulus conditions in $H k$ mutants reveals that there is considerable plasticity for circuit function that could be regulated by the $H k$ channel subunit in normal flies.

\section{DISCUSSION}

This is the first use of Drosophila mutations to examine the influence of identified subunits of $\mathrm{K}^{+}$channels on habituation. The giant fiber pathway system provides a means to link molecular components to cellular physiology within a defined circuit that shows plasticity (Engel and Wu, 1996). Our results establish that different $\mathrm{K}^{+}$channels have distinct functional consequences for habituation in the giant fiber response, with effects as extreme as those of the "learning mutations" rutabaga and dunce (Engel and $\mathrm{Wu}, 1996)$.

\section{Involvement of four potassium channel subunits in habituation}

Potassium currents regulate signal transmission throughout the nervous system, affecting presynaptic neurotransmitter release, postsynaptic integration, and the shape and frequency coding of action potentials (Rudy, 1988; Hille, 1992; Turrigiano et al., 1994). In each of these functions, $\mathrm{K}^{+}$channels have been implicated in neural plasticity (Alkon, 1990; Klein, 1995; Byrne and Kandel, 1996; Debanne et al., 1997; Hoffman et al., 1997). K ${ }^{+}$ channels could have a dual role, as regulators of activitydependent modulation of neural processes leading to plasticity and as targets of modulation. Besides a range of mechanisms at the level of single neurons, habituation may involve various forms of plasticity at the circuit level: conduction of excitatory paths may be depressed, or previously latent inhibitory inputs may be facilitated and recruited (cf. Charpier et al., 1995; Krasne and Teshiba, 1995), and there is often a component of sensitization that could itself involve $\mathrm{K}^{+}$currents (Groves and Thompson, 1970). Therefore, it is essential to study habituation in a defined circuit in the intact organism, to complement work done with model synapses in reduced nervous systems. In this manner, analysis of mutants of identified $\mathrm{K}^{+}$channel subunits has pro- 


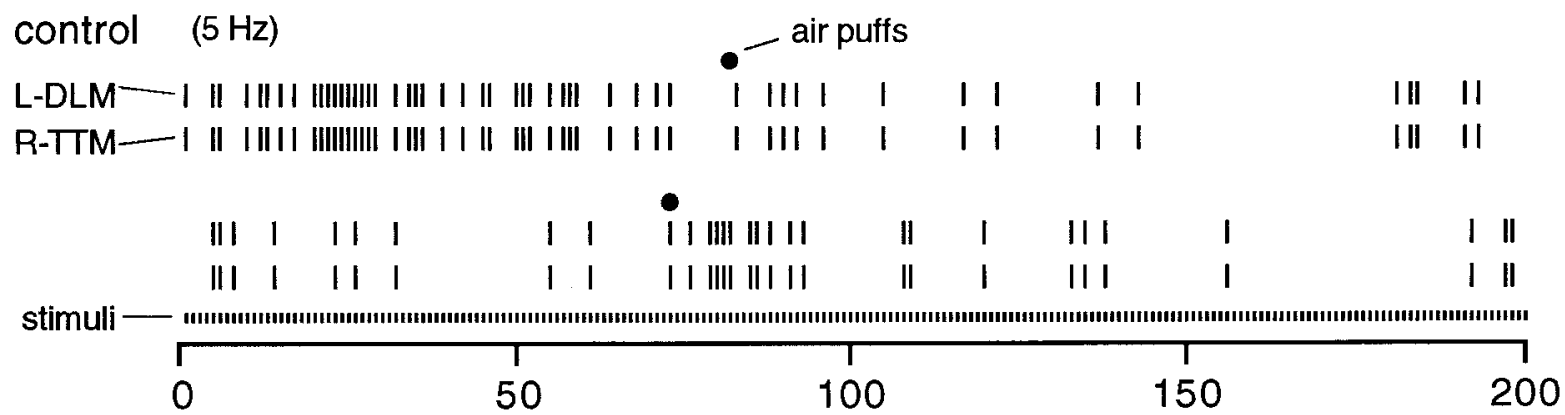

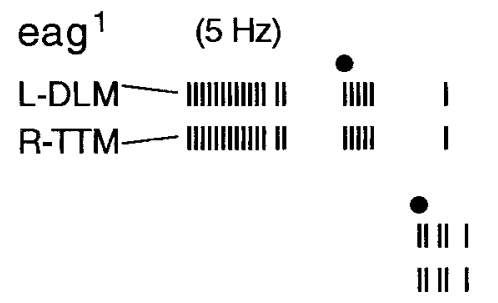

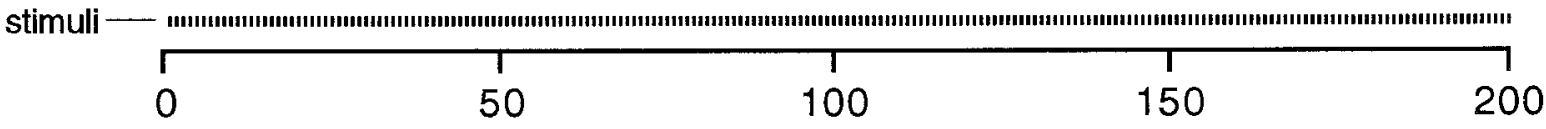

Sh $133 \quad(5 \mathrm{~Hz})$

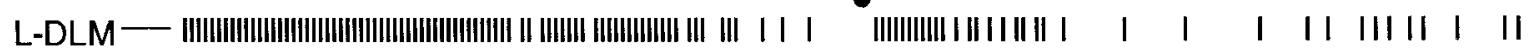

| | | |||||||||||| ||||||||||| | | |||| |||| |||| | ||| || | |||||| || ||||||||| ||| | |||| |

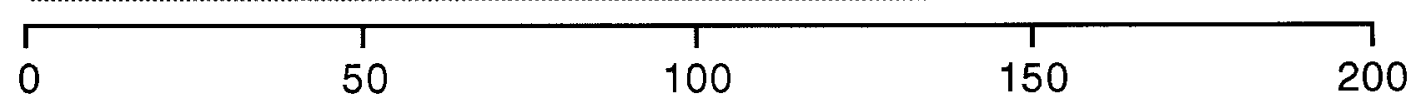

slo $^{1}$

( $8 \mathrm{~Hz}$, reduced V)

DLM/TTM dissoc.

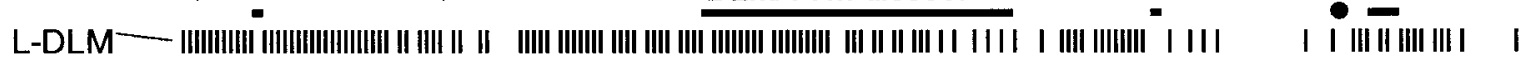

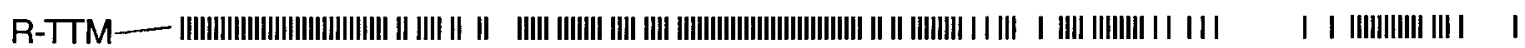
$\downarrow(100$ skipped) $\sqsubset$ further $V$ reduction

II || ||| | |||| | ||| || |||||||||||||| ||||||||||||| ||

1

$\begin{array}{lll}1 & 11 & 1 \\ 1 & 11 & 1\end{array}$

IIIII III III I IIII II II II

IIIII III III I IIII || ||

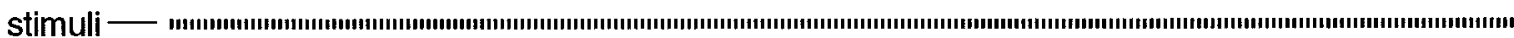

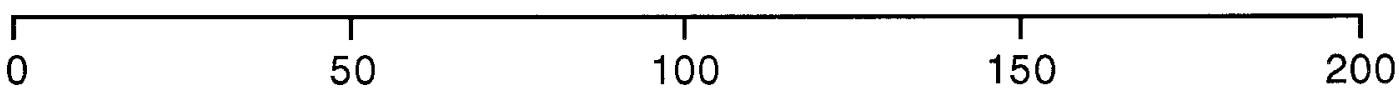

$\mathrm{HK}^{\mathrm{IE} 18}(10 \mathrm{~Hz})$

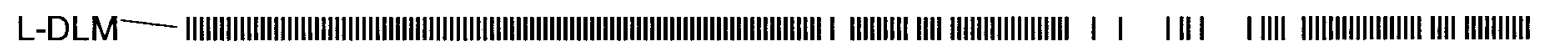

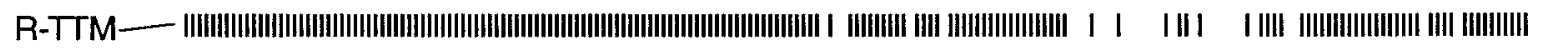

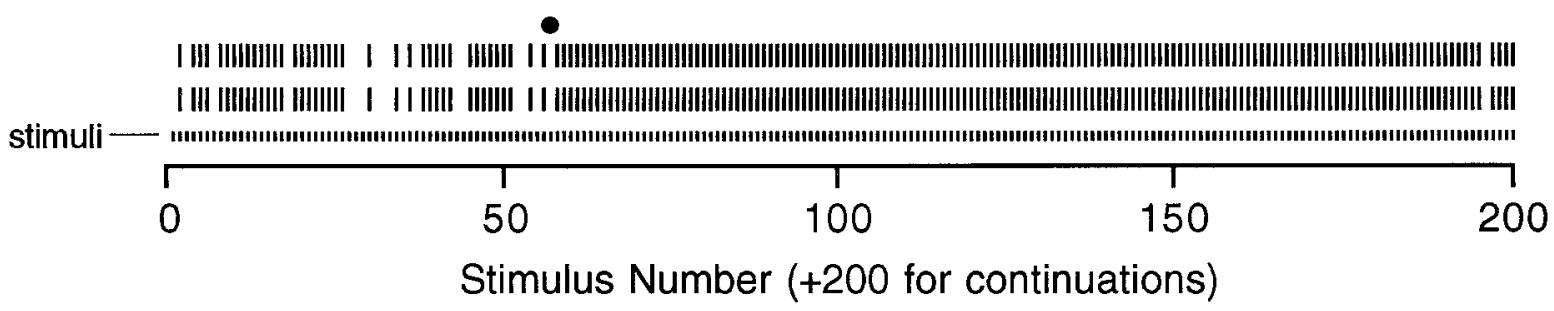



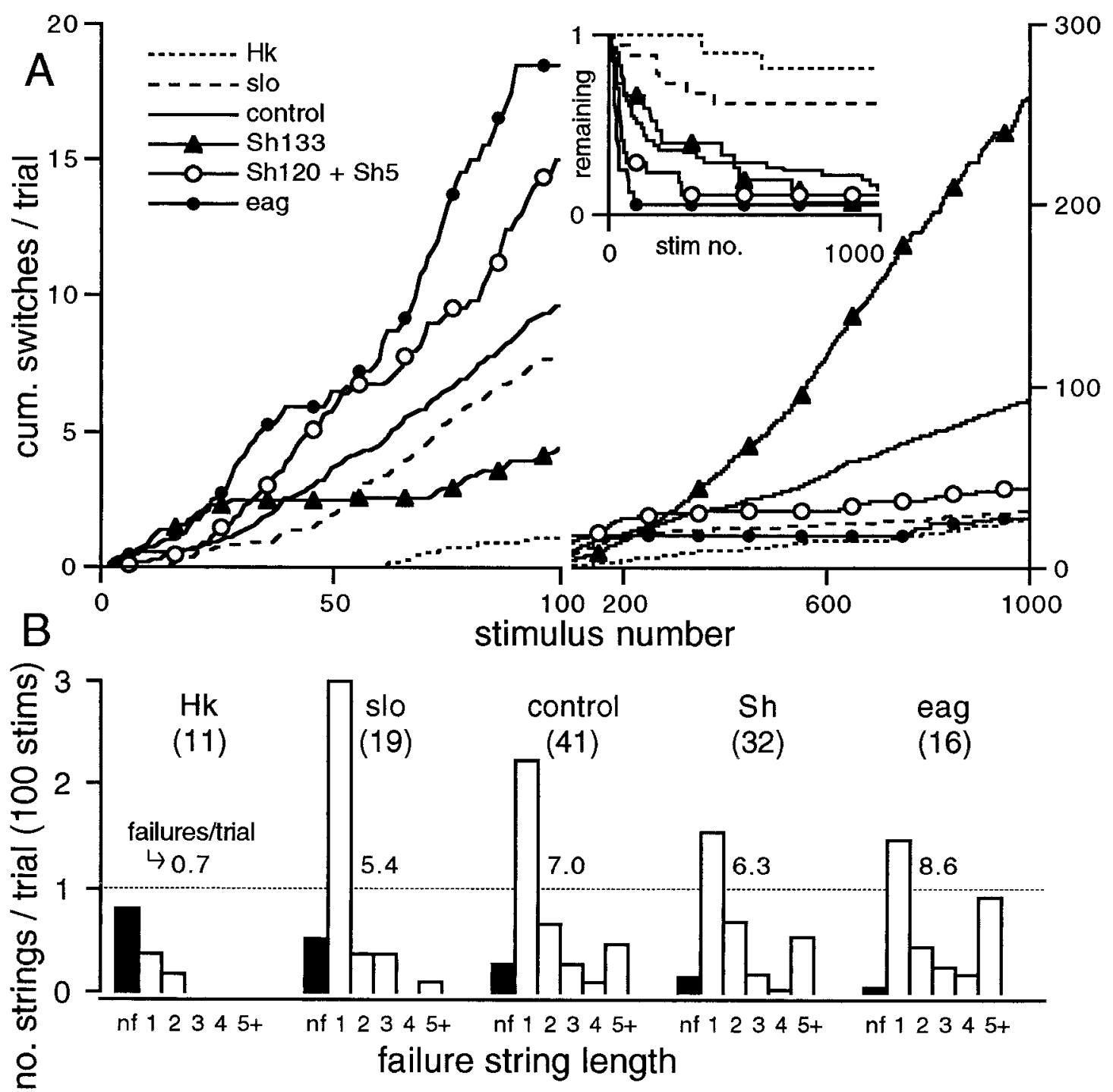

Figure 6. Kinetic properties of habituation in control and mutant flies. $A$, Cumulative frequency of switching between responses and failures (i.e., response after failure or vice versa). Because individual trials were terminated with five consecutive failures, the number of flies still being tested diminished over time (inset shows the proportion remaining). Accordingly, the frequency of switches as shown is per fly per trial at each stimulus $i$ [i.e., (number of switches occurring at $i$ )/(number of flies still being tested at $i$ )], and these weighted frequencies were accumulated for stimuli $i=1-1000$. Note the different scaling of the $x$-axes for $0-100$ versus 100-1000. Line dashing and symbols set on the line are to aid in distinguishing curves. $B$, Distribution of lengths of strings of consecutive failures in first 100 stimuli. String numbers were normalized for each genotype by dividing by the number of trials. Because trials were terminated after five consecutive failures, the five-failure category would also include any longer failure strings $(5+)$. Thus, at most, one $5+$ string could occur in a trial. Conversely, $n f$ (no failures) indicates the proportion of trials without a single failure in the first 100 stimuli. The absolute frequencies of failures (up to trial termination if reached within the first 100 stimuli) are indicated (failures/trial). Sample sizes are indicated (same trials shown in Fig. 3).

duced results that would have been difficult to predict based on other experimental approaches.

The distinct effects of mutations of four $\mathrm{K}^{+}$channel subunits indicate differences in their physiological characteristics and localization within neurons of the pathway. Habituation was enhanced in $S h$ and eag mutants and reduced in slo and $H k$ mutants.
Although Sh and slo subunits are essential for kinetically similar $\mathrm{K}^{+}$currents in muscle (Wei and Salkoff, 1986; Singh and Wu, 1990; Wu and Ganetzky, 1992), their mutations had opposite effects on habituation, perhaps reflecting differences in their activation mechanisms. Sh-type voltage-activated channels are most likely to regulate the shape and frequency coding of sodium

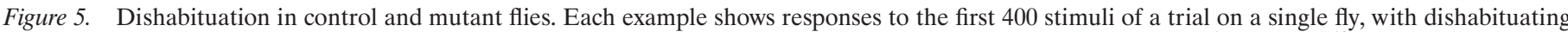

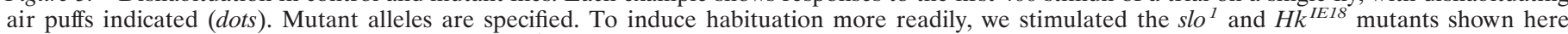

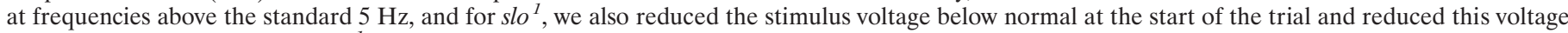

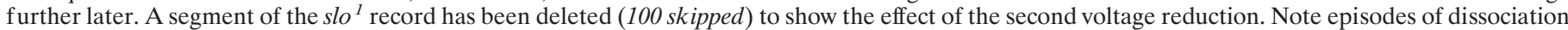

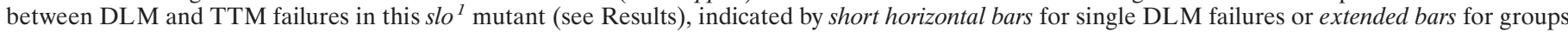
of DLM failures separated by $\leq 15$ stimuli. $L-D L M$, left DLM; R-TTM, right TTM. 

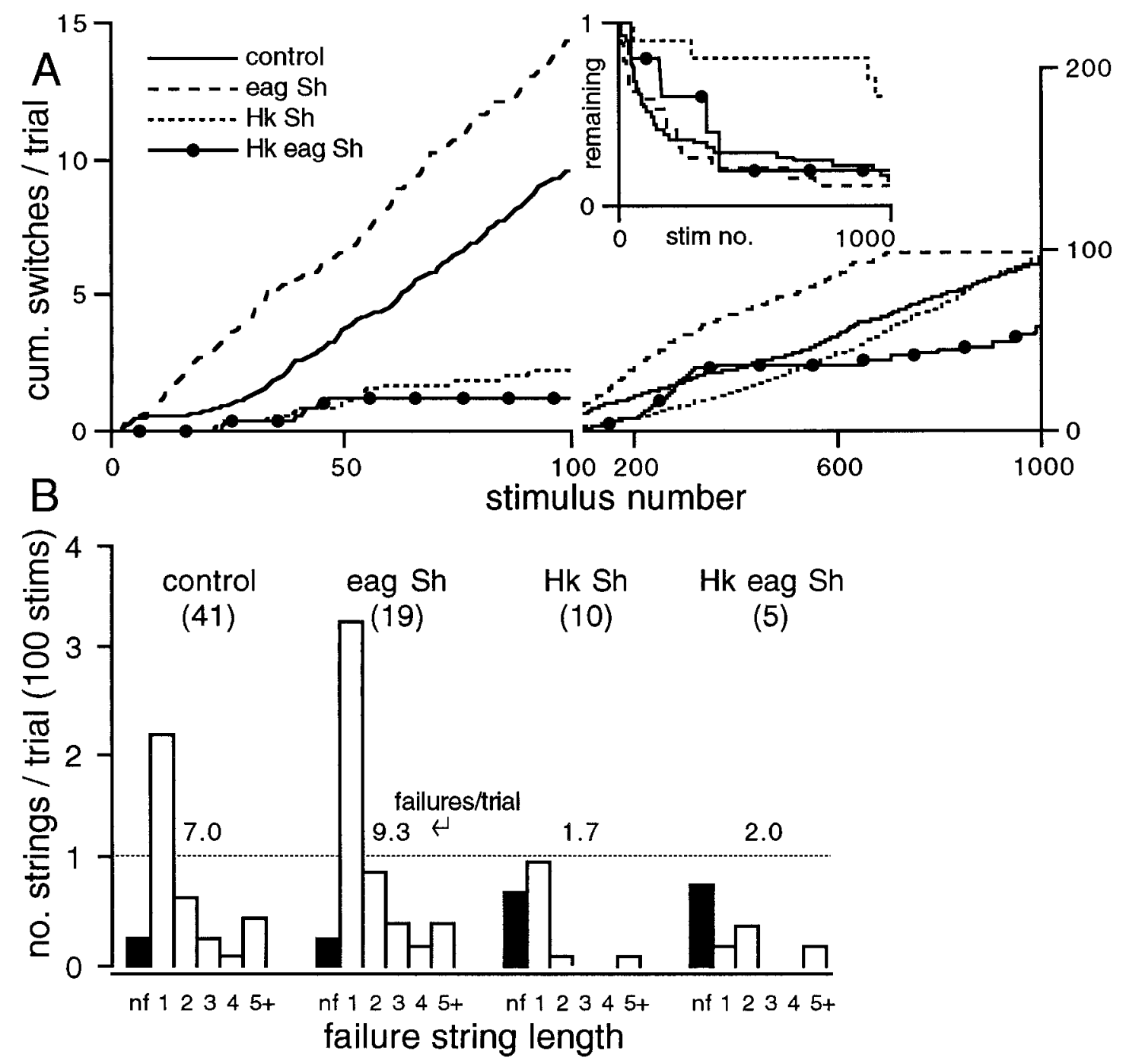

Figure 7. Kinetic properties of habituation in control and mutant combination flies. $A$, Cumulative frequency of switching between responses and failures. $B$, Distribution of failure string lengths in the first 100 stimuli. For explanation, see Figure 6 legend; plots are scaled to match those in Figure 6.

action potentials in axons and dendrites (Tanouye et al., 1981; Debanne et al., 1997; Hoffman et al., 1997). In contrast, slo-type $\mathrm{Ca}^{2+}$-activated $\mathrm{K}^{+}$channels, which can colocalize with presynaptic $\mathrm{Ca}^{2+}$ channels, would be well suited for regulating the activity-dependent accumulation of presynaptic $\mathrm{Ca}^{2+}$ (Augustine et al., 1988; Gho and Ganetzky, 1992; Robitaille and Charlton, 1992; Mallart, 1993; Warbington et al., 1996). Although $S h$ and slo subunits are workhorses in the nervous system, each essential for a specific repolarizing current in muscle and neurons, the most extreme positive and negative changes in habituation rates were induced by mutations of eag and $H k$ subunits that alter $\mathrm{K}^{+}$ current modulation rather than eliminate currents (Zhong and Wu, 1991b, 1993b; Yao and Wu, 1995; Wang and Wu, 1996). Because habituation represents a change over time, it is reasonable that the most important subunits should be those that confer lasting modulation. The opposing direction of eag and $H k$ mutant phenotypes indicates that plasticity may be regulated by counterbalancing mechanisms (Groves and Thompson, 1970). No channel mutations eliminated habituation, which is likely to be shaped by the interaction of multiple channel types, not by a particular "habituation channel." Similarly, mutations that eliminate en- zymes for cAMP metabolism alter habituation but do not prevent it (Engel and Wu, 1996).

Habituation was enhanced by $S h$ alleles $\left(S h^{r K O 120}\right.$ and $\left.S h^{5}\right)$ that alter current density, voltage dependence, or kinetics but was not significantly affected by the antimorphic $S h^{K S 133}$ that (in muscle) eliminates $S h$ current (Wu and Haugland, 1985). This unexpected result implies that $S h$ subunits influence habituation but not as a direct result of their modulation because habituation seemed closer to normal in the absence of functional Sh channels than in the presence of the defective but functional subunits in $S h^{r K O 120}$ and $S h^{5}$ mutants.

The eag channel subunit seems to coassemble into at least four $\mathrm{K}^{+}$channel types in fly tissues (Zhong and Wu, 1991b, 1993b) and can interact with $S h$ subunits to form channels when expressed in Xenopus oocytes (Chen et al., 1996) and the two eag alleles studied alter the modulation of several $\mathrm{K}^{+}$currents in muscle (Zhong and Wu, 1993b; Wu and Chen, 1995). Along with evidence of its modification by kinases and cyclic nucleotides (Warmke et al., 1991; Brüggemann et al., 1993; Zhong and Wu, 1993b; Griffith et al., 1994), this indicates that eag would be an ideal link for the regulation of a broad group of $\mathrm{K}^{+}$channels. If 

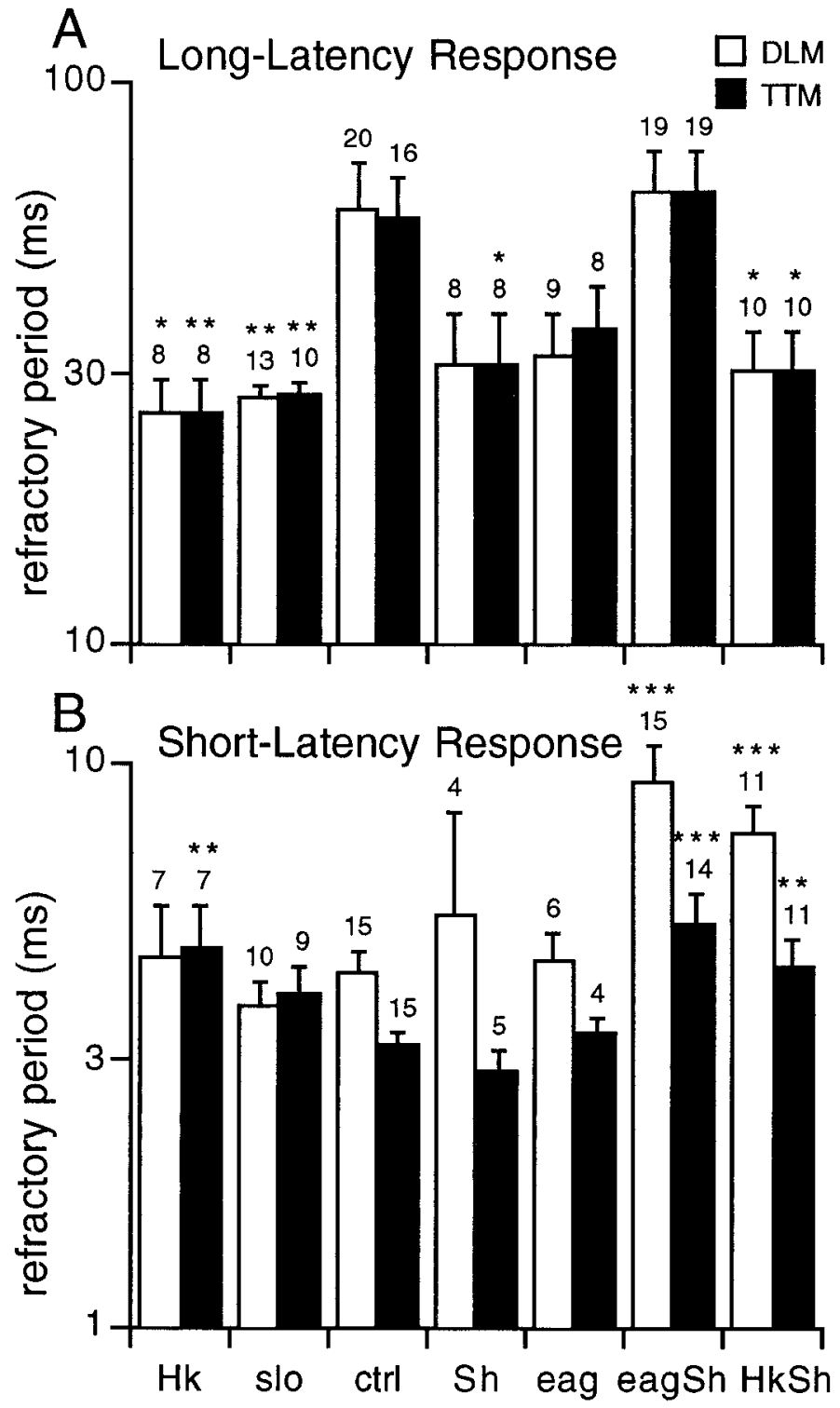

Figure 8. Giant fiber response refractory periods in control and mutant flies (means \pm SEM). Refractory periods were measured as described previously (Engel and $\mathrm{Wu}, 1992,1996)$ and log-transformed for statistics (two-tailed $t$ tests comparing mutants with control). A, Long-latency response. Refractory periods for the long-latency response are nearly always identical for DLM and TTM responses (Engel and Wu, 1996); differences seen here resulted from a few flies in which only DLM was recorded. $B$, Short-latency response. Refractory periods for the shortlatency response are typically different for TTM and DLM pathways (cf. Engel and $\mathrm{Wu}, 1992,1996)$. Sample sizes are indicated above bars; ${ }^{*} p<$ $0.05 ; * *<<0.01 ; * * * p<0.001$. ctrl, Control.

habituation involves the modulation of channels via eag subunits, then a change in the efficacy of modulation could account for accelerated habituation in eag mutants.

The $H k \beta$ subunit is known to associate with and modulate $S h$ channels (Rettig et al., 1994; Chouinard et al., 1995; Rhodes et al., 1995; Yao and Wu, 1995; Wang and Wu, 1996). The importance of this auxiliary subunit in habituation is indicated by the fact that $H k$ mutations produced the most extreme phenotype, sometimes modifying the site of failures as well as slowing the rate of habituation. Habituation may serve to regulate sensitivity to external or internal stimuli (Fischer and Carew, 1993; Bässler and
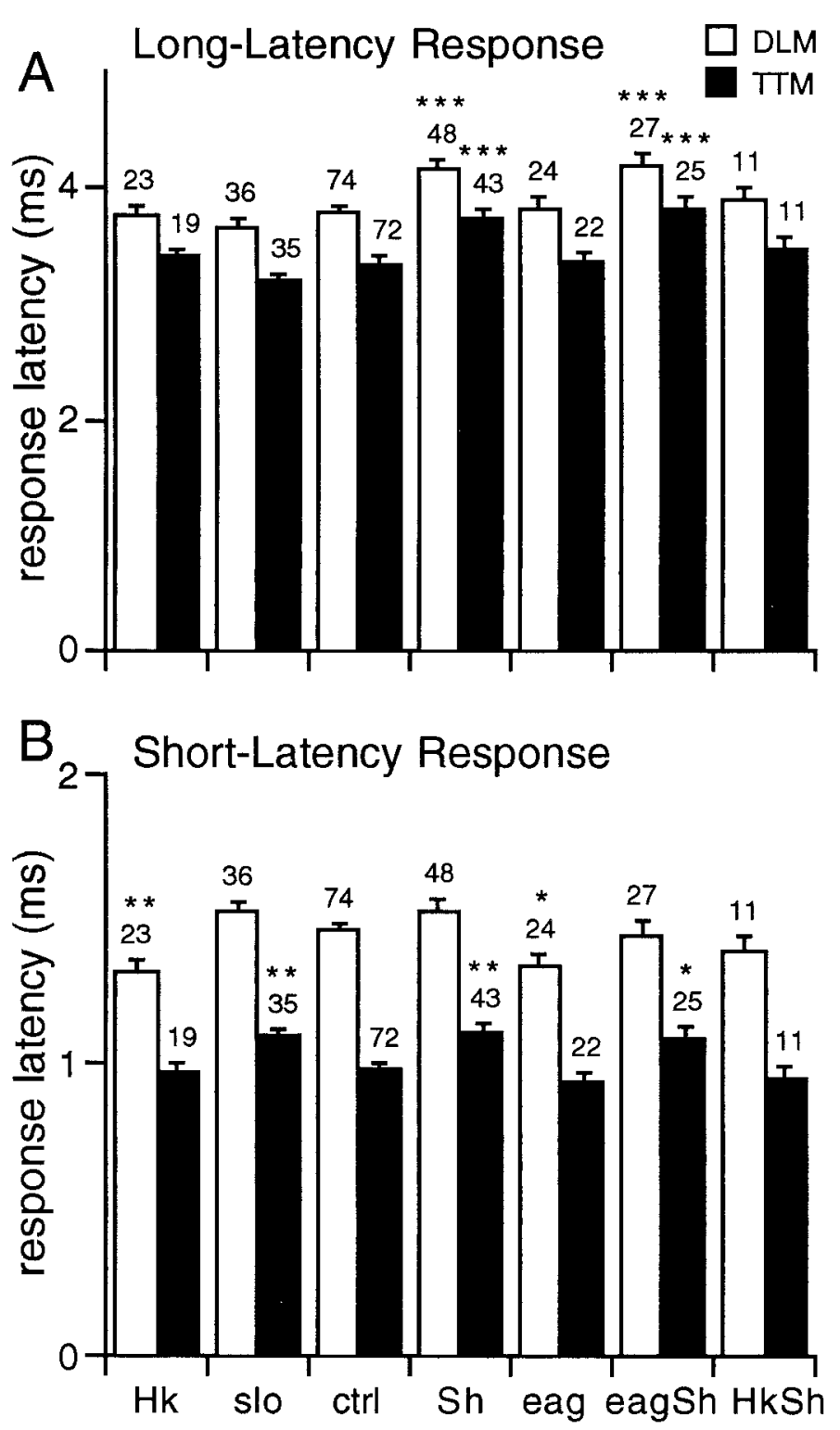

Figure 9. Giant fiber response latencies in control and mutant flies (means \pm SEM), measured as described previously (Engel and $\mathrm{Wu}, 1992$, 1996) and compared using two-tailed $t$ tests (mutants vs controls). $A$, Long-latency response. $B$, Short-latency response. Sample sizes are indicated above bars; ${ }^{*} p<0.05$; ${ }^{*} p<0.01$; ${ }^{* * *} p<0.001$. ctrl, Control.

Nothof, 1994), and it is notable that the visually induced jump response (mediated by the giant fiber pathway) is hypersensitive in $H k$ mutants (Kaplan and Trout, 1969; Levine, 1974). This hypersensitivity is less extreme when $H k$ is combined with $S h$ (Kaplan and Trout, 1974), consistent with our results in multiple mutants (Figs. 2, 3). Likewise, abnormal spontaneous rhythmic firing seen in cultured $H k$ neurons becomes less extreme in $H k \mathrm{Sh}$ double mutant neurons (Yao and Wu, 1995).

Mutations of $S h$ affected habituation less strongly than did either $e a g$ or $H k$. If $e a g$ and $H k$ subunits modify $S h$ currents, as has been proposed, then it seems that plasticity is disrupted by the maladjustment of modulatory mechanisms (in eag or $H k$ mutants) far more than by the alteration or elimination of their target $(S h)$ channels. $H k$ subunits have so far only been shown to associate with $S h$ channels; yet even though $S h^{K S 133}$ eliminates functional 

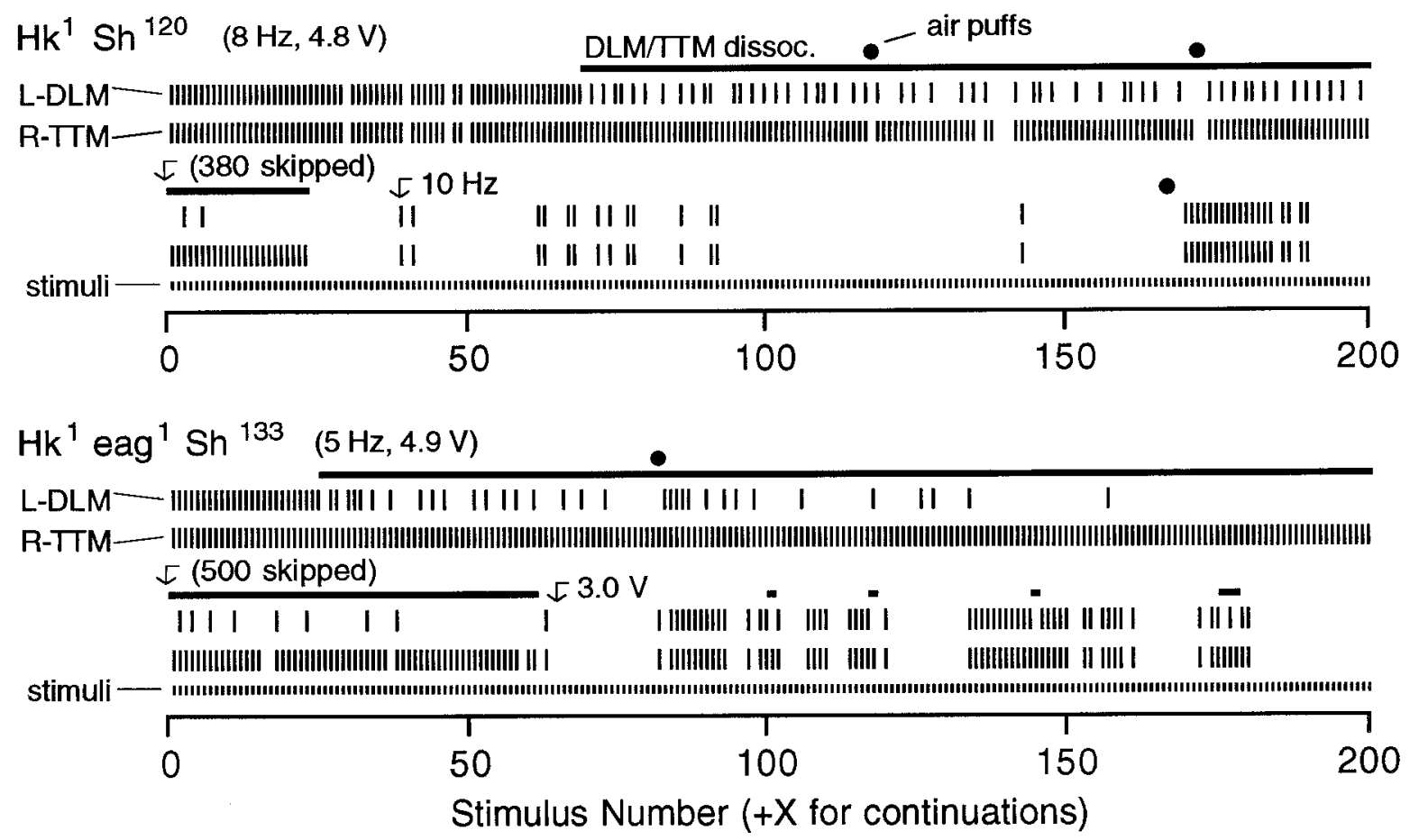

Figure 10. Decoupling of DLM and TTM long-latency responses during habituation in Hk-combination mutants. Layout is as described in Figure 5; a segment of each record has been deleted (skipped) to show transitions between decoupling and coupling of responses. Episodes of dissociation between DLM and TTM failures are indicated by horizontal bars as in Figure 5. Note that during the $H k^{1} S h^{r K O}{ }^{20}$ trial, stimulus frequency was increased as indicated; in the $\mathrm{Hk}^{1} \mathrm{eag}^{1} \mathrm{Sh}^{\mathrm{KS} 133}$ trial, stimulus voltage was reduced to $3.2 \mathrm{~V}$ during the deleted segment and further reduced to $3.0 \mathrm{~V}$ at the point indicated.

Sh channels (Chouinard et al., 1995; Wang and Wu, 1996), $H k^{1}$ $e{ }^{1}{ }^{1} S^{K S 133}$ differed markedly from $e^{K a g^{1}} S h^{K S 133}$, and $H k S h$ differed from $S h$ (Figs. 2, 3, 7, Table 1). The $H k$ subunit may therefore prove to modulate other $\mathrm{K}^{+}$channels besides $\mathrm{Sh}$, potentially including products of the genes sei, shal, shab, and shaw (Butler et al., 1989; Tsunoda and Salkoff, 1995; Titus et al., 1996; Wang et al., 1996) that were not examined here.

Characteristics of habituation for a given behavior can depend critically on the interstimulus interval (ISI) (e.g., Groves and Thompson, 1970; Davis, 1984; Boulis and Sahley, 1988), and it is possible that $\mathrm{K}^{+}$channels play different roles in habituation at different ISIs. A broad range of ISIs have been used in the study of behavioral habituation in diverse phyla: less than a second (May and Hoy, 1991), seconds (Thompson and Spencer, 1966; Davis, 1984; Wittekind and Spatz, 1988; Corfas and Dudai, 1989), tens of seconds to minutes (Pinsker et al., 1970; Long et al., 1989; Rankin and Broster, 1992; Krasne and Teshiba, 1995; Weil and Weeks, 1996), or hours (Brown et al., 1996). The visually induced jump response in Drosophila habituates at ISIs of 1-10 sec (Engel and $\mathrm{Wu}, 1996)$. In the present experiments, an ISI of $0.2 \mathrm{sec}(5$ $\mathrm{Hz}$ ) was used; the kinetics of habituation are not expected to be identical because visual stimulation may recruit only a subset of the cervical giant fiber afferents that are activated by the electrical stimulation used here (Fig. 1).

\section{Potassium channels and the mutational analysis of learning and memory}

The classical approach to the genetic analysis of learning and memory sought mutations or transformants without obvious confounding behavioral or developmental defects. This led to genes involved with various second messenger pathways, including rutabaga, dunce, and amnesiac (cAMP cascade), ala (CaM-kinase), and KCI and turnip (protein kinase C) (Dudai, 1988; Choi et al., 1991; Tully, 1991; Griffith et al., 1993; Feany and Quinn, 1995; Davis, 1996; Kane et al., 1997), but tended to exclude ion channel mutations because these caused easily detectable behavioral defects such as ether-induced leg shaking (Dudai, 1988). It seems unlikely that the changes in habituation performance shown here in channel mutants are a spurious consequence of pleiotropic defects elsewhere in the circuit, because the response attenuation in mutants was localized to the afferent stage of the circuit where habituation ordinarily occurs (see Results) and showed recovery and habituation that appeared grossly normal.

In fact, concerns about pleiotropy also apply to classical learning mutations such as dnc (Dudai, 1988; Qui and Davis, 1993). The distinction between "pure" learning mutations and mutations with secondary physiological, developmental, or behavioral effects is now blurred. It has become clear that mutations of ion channels and second messenger systems have overlapping effects (Dudai, 1988; Davis, 1996; Wu, 1996). Mutations affecting $\mathrm{K}^{+}$ channel subunits alter activity-dependent conditioning of neural excitability and firing (Ikeda and Kaplan, 1970; Tanouye et al., 1981; Ganetzky and Wu, 1982; Saito and Wu, 1991, 1992) and synaptic efficacy (Jan et al., 1977; Ganetzky and Wu, 1983; Mallart, 1993; Delgado et al., 1994; Warbington et al., 1996). However, second messengers modulate ion channels, and mutations of second messenger pathways cause physiological effects resembling channel mutations. rut and $d n c$ mutations that alter cAMP metabolism have been shown to alter muscle $\mathrm{K}^{+}$currents (Zhong and $\mathrm{Wu}, 1993 \mathrm{a}$ ), excitability in cultured neurons (Zhao and $\mathrm{Wu}$, 1997), and facilitation at neuromuscular junctions (Zhong and $\mathrm{Wu}, 1991 \mathrm{a})$. Branching of motor neuron terminals is increased by $e a g, S h$, and $H k$ mutations that increase neural activity (Budnik et 
al., 1990), but cAMP metabolic mutations have identical effects. Indeed, the most extreme terminal branching occurs in dnc eag and $d n c S h$ double mutants and is suppressed by rut in triple mutants (Zhong et al., 1992). On the other hand, channel mutations can alter behavioral plasticity. Mutations of $S h$ and eag reduce conditioning in courtship (Cowan and Siegel, 1984; Griffith et al., 1994) and alter habituation of a jump response to olfactory stimulation (McKenna et al., 1989; Tully and Koss, 1992) (C.-F. Wu and T. Tully, unpublished observations), and Sh mutations alter classical olfactory conditioning (Cowan and Siegel, 1986).

We have shown here that mutations of four different $\mathrm{K}^{+}$ channel subunits alter habituation of the giant fiber response in gene-specific ways, with modulatory eag and $H k$ subunits appearing particularly influential. In the future, expression of normal or mutated genes may be concentrated in particular regions of the nervous system using gynandromorph mosaics or enhancer trap lines or temporally controlled with conditional promoters (Burg et al., 1993; Ferveur et al., 1995; Zhao et al., 1995; Han et al., 1996; Cambridge et al., 1997). The effects of such novel spatial or temporal patterns of mutant gene expression can be contrasted with the phenotypes of mutations expression patterns closer to normal, such as those used in this study, to give indications of the localization of habituation and the colocalization and potential interaction of different molecular players. More broadly, these results open the possibility to compare the effects of channel mutations and second messenger mutations at cellular, circuit, and behavioral levels within a single system.

\section{REFERENCES}

Alkon DL (1990) Biophysics of memory. In: Potassium channels: basic function and therapeutic aspects (Colatsky TJ, ed), pp 273-277. New York: Liss.

Atkinson NS, Robertson GA, Ganetzky B (1991) A component of calcium-activated potassium channels encoded by the Drosophila slo locus. Science 253:551-554.

Augustine GJ, Charlton MP, Horn R (1988) Role of calcium-activated potassium channels in transmitter release at the squid giant synapse. J Physiol (Lond) 398:149-164.

Baird DH, Schalet AP, Wyman RJ (1990) The Passover locus in Drosophila melanogaster: complex complementation and different effects on the giant fiber neural pathway. Genetics 126:1045-1059.

Baro DJ, Levini RM, Kim MT, Willms AR, Lanning CC, Rodriguez HE, Harris-Warrick RM (1997) Quantitative single-cell-reverse transcription-PCR demonstrates that A-current magnitude varies as a linear function of shal gene expression in identified stomatogastric neurons. J Neurosci 17:6597-6610.

Bässler U, Nothof U (1994) Gain control in a proprioceptive feedback loop as a prerequisite for working close to instability. J Comp Physiol [A] 175:23-33.

Becker MN, Brenner R, Atkinson NS (1995) Tissue-specific expression of a Drosophila calcium-activated potassium channel. J Neurosci 15:6250-6259.

Boulis NM, Sahley CL (1988) A behavioral analysis of habituation and sensitization of shortening in the semi-intact leech. J Neurosci 8:4621-4627.

Brown GD, Frost WN, Getting PA (1996) Habituation and iterative enhancement of multiple components of the Tritonia swim response. Behav Neurosci 110:478-485.

Brüggemann A, Pardo LA, Stühmer W, Pongs O (1993) ether à go-go encodes a voltage-gated channel permeable to $\mathrm{K}^{+}$and $\mathrm{Ca}^{2+}$ and modulated by cAMP. Nature 365:445-448.

Budnik V, Zhong Y, Wu C-F (1990) Morphological plasticity of motor axons in Drosophila mutants with altered excitability. J Neurosci 10:3754-3768.

Burg MG, Hanna L, Kim Y-T, Wu C-F (1993) Development and maintenance of a simple reflex circuit in small-patch mosaics of Drosophila: effects of altered neuronal function and developmental arrest. J Neurobiol 24:803-823.
Butler A, Wei A, Baker K, Salkoff L (1989) A family of putative potassium channel genes in Drosophila. Science 243:943-947.

Byrne JH, Kandel ER (1996) Presynaptic facilitation revisited: state and time dependence. J Neurosci 16:425-435.

Cambridge SB, Davis RL, Minden J (1997) Drosophila mitotic domain boundaries as cell fate boundaries. Science 277:825-828.

Charpier S, Behrends JC, Triller A, Faber D-S, Korn H (1995) "Latent" inhibitory connections become functional during activity-dependent plasticity. Proc Natl Acad Sci USA 92:117-120.

Chen M-L, Hoshi T, Wu C-F (1996) Heteromultimeric interactions among $\mathrm{K}^{+}$channel subunits from Shaker and eag families in Xenopus oocytes. Neuron 17:535-542.

Choi K-W, Smith RF, Buratowski RM, Quinn WG (1991) Deficient protein kinase C activity in turnip, a Drosophila learning mutant. J Biol Chem 266:15999-16006.

Chouinard SW, Wilson GF, Schlimgen AK, Ganetzky B (1995) A potassium channel $\beta$ subunit, related to the aldo-keto reductase superfamily, encoded by the Drosophila Hyperkinetic locus. Proc Natl Acad Sci USA 92:6763-6767.

Corfas G, Dudai Y (1989) Habituation and dishabituation of a cleaning reflex in normal and mutant Drosophila. J Neurosci 9:56-62.

Cowan TM, Siegel RW (1984) Mutational and pharmacological alterations of neuronal membrane function disrupt conditioning in Drosophila. J Neurogenet 1:333-344.

Cowan TM, Siegel RW (1986) Drosophila mutations that alter ionic conduction disrupt acquisition and retention of a conditioned odor avoidance response. J Neurogenet 3:187-201.

Davis M (1984) The mammalian startle response. In: Neural mechanisms of startle behavior (Eaton RC, ed), pp 287-351. New York: Plenum.

Davis RL (1996) Physiology and biochemistry of Drosophila learning mutants. Physiol Rev 76:299-317.

Debanne D, Guérineau NC, Gähwiler BH, Thompson SM (1997) Action-potential propagation gated by an axonal $\mathrm{I}_{\mathrm{A}}$-like $\mathrm{K}^{+}$conductance in hippocampus. Nature 389:286-289.

Delgado R, Latorre R, Labarca P (1994) Shaker mutants lack posttetanic potentiation at motor end-plates. Eur J Neurosci 6:1160-1166.

Dudai Y (1988) Neurogenetic dissection of learning and short-term memory in Drosophila. Annu Rev Neurosci 11:537-563.

Elkins T, Ganetzky B (1990) Conduction in the giant nerve fiber pathway in temperature-sensitive paralytic mutants of Drosophila. J Neurogenet 6:207-219.

Elkins T, Ganetzky B, Wu C-F (1986) A Drosophila mutation that eliminates a calcium-dependent potassium current. Proc Natl Acad Sci USA 83:8415-8419.

Engel JE (1995) Effects of second messenger and excitability mutations upon identified neural circuits underlying activity-dependent plasticity of behavior in Drosophila. PhD thesis, University of Iowa.

Engel JE, Wu C-F (1992) Interactions of membrane excitability mutations affecting potassium and sodium currents in the flight and giant fiber escape systems of Drosophila. J Comp Physiol [A] 171:93-104.

Engel JE, Wu C-F (1996) Alteration of non-associative conditioning of an identified escape circuit in Drosophila memory mutants. J Neurosci 16:3486-3499.

Feany MB, Quinn WG (1995) A neuropeptide gene defined by the Drosophila memory mutant amnesiac. Science 268:869-873.

Ferveur JF, Stortkuhl KF, Stocker RF, Greenspan RJ (1995) Genetic feminization of brain structures and changed sexual orientation in male Drosophila. Science 267:902-905.

Fischer TM, Carew TJ (1993) Activity-dependent potentiation of recurrent inhibition: a mechanism for dynamic gain control in the siphon withdrawal reflex of Aplysia. J Neurosci 13:1302-1314.

Fitzgerald K, Wright WG, Marcus EA, Carew TJ (1990) Multiple forms of non-associative plasticity in Aplysia: a behavioural, cellular and pharmacological analysis. Philos Trans R Soc Lond [Biol] 329:171-178.

Ganetzky B, Wu C-F (1982) Drosophila mutants with opposing effects on nerve excitability: genetic and spatial interactions in repetitive firing. J Neurophysiol 47:501-514.

Ganetzky B, Wu C-F (1983) Neurogenetic analysis of potassium currents in Drosophila: synergistic effects on neuromuscular transmission in double mutants. J Neurogenet 1:17-28.

Ganetzky B, Warmke JW, Robertson G, Pallanck L (1995) New potassium channel gene families in flies and mammals: from mutants to molecules. In: Ion channels and genetic diseases (Dawson DC, Frizzell RA, eds), pp 29-39. New York: Rockefeller UP. 
Gautam M, Tanouye MA (1990) Alteration of potassium channel gating: molecular analysis of the Drosophila $S h^{5}$ mutation. Neuron 5:67-73.

Gho M, Ganetzky B (1992) Analysis of repolarization of presynaptic motor terminals in Drosophila larvae using potassium-channel-blocking drugs and mutations. J Exp Biol 170:93-111.

Griffith LC, Verselis LM, Aitken KM, Kyriacou CP, Danho W, Greenspan RJ (1993) Inhibition of calcium/calmodulin-dependent protein kinase in Drosophila disrupts behavioural plasticity. Neuron 10:501-509.

Griffith LC, Wang J, Zhong Y, Wu C-F, Greenspan RJ (1994) Calcium/ calmodulin-dependent protein kinase II and potassium channel subunit Eag similarly affect plasticity in Drosophila. Proc Natl Acad Sci USA 91:10044-10048.

Groves PM, Thompson RF (1970) Habituation: a dual-process theory. Psychol Rev 77:419-450.

Hall J (1982) Genetics of the nervous system in Drosophila. Q Rev Biophys 15:223-479.

Han PL, Meller V, Davis RL (1996) The Drosophila brain revisited by enhancer detection. J Neurobiol 31:88-102.

Haugland F, Wu C-F (1990) A voltage-clamp analysis of gene-dosage effects of the Shaker locus on larval muscle potassium currents in Drosophila. J Neurosci 10:1357-1371.

Hille B (1992) Ionic channels of excitable membranes, 2nd Edition. Sunderland, MA: Sinauer.

Hoffman DA, Magee JC, Colbert CM, Johnston D (1997) $\mathrm{K}^{+}$channel regulation of signal propagation in dendrites of hippocampal pyramidal neurons. Nature 387:869-875.

Ikeda K, Kaplan WD (1970) Patterned neural activity of mutant Drosophila melanogaster. Proc Natl Acad Sci USA 66:765-772.

Ikeda K, Koenig JH (1988) Morphological identification of the motor neurons innervating the dorsal longitudinal flight muscle of Drosophila melanogaster. J Comp Neurol 273:436-444.

Isacoff EY, Jan YN, Jan LY (1990) Evidence for the formation of heteromultimeric potassium channels in Xenopus oocytes. Nature 345:530-534.

Iverson L, Tanouye M, Lester H, Davidson N, Rudy B (1988) A-type potassium channels expressed from Shaker locus cDNA. Proc Natl Acad Sci USA 85:5723-5727.

Jan LY, Jan YN (1990) How might the diversity of potassium channels be generated? Trends Neurosci 13:415-419.

Jan Y, Jan L, Dennis M (1977) Two mutations of synaptic transmission in Drosophila. Proc R Soc Lond [Biol] 198:87-108.

Kane NS, Robichon A, Dickinson JA, Greenspan RJ (1997) Learning without performance in PKC-deficient Drosophila. Neuron 18:307-314.

Kaplan W, Trout WI (1969) The behavior of four neurological mutants of Drosophila. Genetics 61:399-409.

Kaplan WD, Trout WE (1974) Genetic manipulation of an abnormal jump response in Drosophila. Genetics 77:721-739.

King DG, Wyman RJ (1980) Anatomy of the giant fibre pathway in Drosophila. I. Three thoracic components of the pathway. J Neurocytol 9:753-770.

Klein M (1995) Modulation of ion currents and regulation of transmitter release in short-term synaptic plasticity: the rise and fall of the action potential. Invert Neurosci 1:15-24.

Klein M, Shapiro E, Kandel ER (1980) Synaptic plasticity and the modulation of the $\mathrm{Ca}^{2+}$ current. J Exp Biol 89:117-157.

Komatsu A, Singh S, Rathe P, Wu C-F (1990) Mutational and gene dosage analysis of calcium-activated potassium channels in Drosophila: correlation of micro- and macroscopic currents. Neuron 4:313-321.

Krasne FB, Teshiba TM (1995) Habituation of an invertebrate escape reflex due to modulation by higher centers rather than local events. Proc Natl Acad Sci USA 92:3362-3366.

Levine J (1974) Giant neuron input in mutant and wild type Drosophila. J Comp Physiol [A] 93:265-285.

Levine J, Tracey D (1973) Structure and function of the giant motoneuron of Drosophila melanogaster. J Comp Physiol [A] 87:213-235.

Lichtinghagen R, Stocker M, Wittka R, Boheim G, Stühmer W, Ferrus A, Pongs O (1990) Molecular basis of altered excitability in Shaker mutants of Drosophila melanogaster. EMBO J 9:4399-4407.

Lin M, Nash HA (1996) Influence of general anesthetics on a specific neural pathway in Drosophila melanogaster. Proc Natl Acad Sci USA 93:10446-10451.

Lindsley DL, Zimm GG (1992) The genome of Drosophila melanogaster. San Diego: Academic.

Long TM, Hanlon RT, Maat AT, Pinsker HM (1989) Non-associative learning in the squid Lolliguncula brevis (Mollusca, Cephalopoda). Mar Behav Physiol 16:1-9.

Mallart A (1993) Calcium-dependent modulation of the facilitation of transmitter release at neuromuscular junctions of Drosophila. J Physiol (Paris) 87:83-88.

May ML, Hoy RR (1991) Habituation of the ultrasound-induced acoustic startle response in flying crickets. J Exp Biol 159:489-499.

McCormick K, Lin J-W, Iverson LE, Rudy B (1990) Shaker $\mathrm{K}^{+}$channel subunits form heteromultimeric channels with novel functional properties. Biochem Biophys Res Commun 171:1361-1371.

McKenna M, Monte P, Helfand SL, Woodard C, Carlson J (1989) A simple chemosensory response in Drosophila and the isolation of $a c j$ mutants in which it is affected. Proc Natl Acad Sci USA 86:8118-8122.

Mottes JR, Iverson LE (1995) Tissue-specific alternative splicing of hybrid Shaker/lacZ genes correlates with kinetic differences in Shaker $\mathrm{K}^{+}$ currents in vivo. Neuron 14:613-623.

Pinsker HM, Kupfermann I, Castellucci VF, Kandel ER (1970) Habituation and dishabituation of the gill-withdrawal reflex in Aplysia. Science 167:1740-1742.

Qui Y, Davis RL (1993) Genetic dissection of the learning/memory gene dunce of Drosophila melanogaster. Genes Dev 7:1447-1458.

Rankin CH, Broster BS (1992) Factors affecting habituation and recovery from habituation in the nematode Caenorhabditis elegans. Behav Neurosci 106:239-249.

Rehm H, Tempel BL (1991) Voltage-gated $\mathrm{K}^{+}$channels of the mammalian brain. FASEB J 5:164-170.

Rettig J, Heinemann SH, Wunder F, Lorra C, Parcej DN, Dolly JO, Pongs O (1994) Inactivation properties of voltage-gated $\mathrm{K}^{+}$channels altered by presence of $\beta$-subunit. Nature 369:289-294.

Rhodes KJ, Keilbaugh SA, Barrezueta NX, Lopez KL, Trimmer JS (1995) Association and colocalization of $\mathrm{K}^{+}$channel $\alpha$ - and $\beta$-subunit polypeptides in rat brain. J Neurosci 15:5360-5371.

Robitaille R, Charlton MP (1992) Presynaptic calcium signals and transmitter release are modulated by calcium-activated potassium channels. J Neurosci 12:297-305.

Rudy B (1988) Diversity and ubiquity of K channels. Neuroscience 25:729-749.

Ruppersberg JP, Schröter KH, Sakmann B, Stocker M, Sewing S, Pongs O (1990) Heteromultimeric channels formed by rat brain potassiumchannel proteins. Nature 345:535-537.

Saito M, Wu C-F (1991) Expression of ion channels and mutational effects in giant Drosophila neurons differentiated from cell divisionarrested embryonic neuroblasts. J Neurosci 11:2135-2150.

Saito M, Wu C-F (1992) Ionic channels in cultured Drosophila neurons. In: Invertebrate molecular neurobiology (Pichon Y, ed), pp 366-389. Basel: Birkhauser.

Salkoff L, Wyman R (1981) Genetic modification of potassium channels in Drosophila Shaker mutants. Nature 293:228-230.

Salkoff L, Baker K, Butler A, Covarrubias M, Pak MD, Wei A (1992) An essential "set" of $\mathrm{K}^{+}$channels conserved in flies, mice and humans. Trends Neurosci 15:161-166.

Schwarz T, Papazian D, Carretto R, Jan Y-N, Jan L (1990) Immunological characterization of $\mathrm{K}^{+}$channel components from the Shaker locus and differential distribution of splicing variants in Drosophila. Neuron 2:119-127.

Schwarz TL, Tempel BL, Papazian DM, Jan YN, Jan LY (1988) Multiple potassium-channel components are produced by alternative splicing at the Shaker locus in Drosophila. Nature 331:137-142.

Singh S, Wu C-F (1990) Properties of potassium currents and their role in membrane excitability in Drosophila larval muscle fibers. J Exp Biol 152:59-76.

Stern M, Ganetzky B (1989) Altered synaptic transmission in Drosophila Hyperkinetic mutants. J Neurogenet 5:215-228.

Stocker M, Stühmer W, Wittka R, Wang X, Müller R, Ferrus A, Pongs O (1990) Alternative Shaker transcripts express either rapidly inactivating or noninactivation $\mathrm{K}^{+}$channels. Proc Natl Acad Sci USA 87:8903-8907.

Strausfeld NJ, Bassemir UK (1983) Cobalt-coupled neurons of a giant fibre system in Diptera. J Neurocytol 12:971-991.

Tanouye MA, Wyman RJ (1980) Motor outputs of giant nerve fiber in Drosophila. J Neurophysiol 44:405-421.

Tanouye MA, Ferrus A, Fujita SC (1981) Abnormal action potentials associated with the Shaker complex locus of Drosophila. Proc Natl Acad Sci USA 78:6548-6552. 
Thompson RF, Spencer WA (1966) Habituation: a model phenomenon for the study of neuronal substrates of behavior. Psychol Rev 73:16-43.

Timpe L, Schwarz T, Tempel B, Papazian D, Jan Y, Jan L (1988) Expression of functional potassium channels from Shaker cDNA in Xenopus oocytes. Nature 331:143-145.

Titus SA, Warmke JW, Ganetzky B (1997) The Drosophila erg K+ channel polypeptide is encoded by the seizure locus. J Neurosci 17:875-881.

Trimarchi JR, Schneiderman AM (1993) Giant fiber activation of an intrinsic muscle in the mesothoracic leg of Drosophila melanogaster. J Exp Biol 177:149-167.

Tseng-Crank J, Pollack J, Hayashi I, Tanouye M (1991) Expression of ion channels in Drosophila. J Neurogenet 7:229-239.

Tsunoda S, Salkoff L (1995) Genetic analysis of Drosophila neurons: Shal, Shaw, and Shab encode most embryonic potassium currents. J Neurosci 15:1741-1754.

Tully T (1991) Genetic dissection of learning and memory in Drosophila melanogaster. In: Neurobiology of learning, emotion and affect (Madden IV J, ed), pp 29-66. New York: Raven.

Tully T, Koss S (1992) Habituation of the jump reflex to olfactory cues in normal and mutant Drosophila. Soc Neurosci Abstr 18:942.

Turrigiano G, Abbott LF, Marder E (1994) Activity-dependent changes in the intrinsic properties of cultured neurons. Science 264:974-977.

Wang J, Wu C-F (1996) In vivo functional role of the Drosophila Hyperkinetic $\beta$ subunit in gating and inactivation of Shaker $\mathrm{K}^{+}$channels. Biophys J 71:3167-3176.

Wang X, Reynolds ER, Deak P, Hall LM (1997) The seizure locus encodes the Drosophila homolog of the HERG potassium channel. J Neurosci 17:882-890.

Warbington L, Hillman T, Adams C, Stern M (1996) Reduced transmitter release conferred by mutations in the slowpoke-encoded $\mathrm{Ca}^{2+}$ activated $\mathrm{K}^{+}$channel gene of Drosophila. Invert Neurosci 2:51-60.

Warmke J, Drysdale R, Ganetzky B (1991) A distinct potassium channel polypeptide encoded by the Drosophila eag locus. Science 252:1560-1562.

Wei A, Salkoff L (1986) Occult Drosophila calcium channels and twinning of calcium and voltage-activated potassium channels. Science 233:780-782.

Weil DE, Weeks JC (1996) Habituation and dishabituation of the proleg withdrawal reflex in larvae of the hawk moth Manduca sexta. Behav Neurosci 110:1133-1147.
Wittekind WC, Spatz H-C (1988) Habituation of the landing response of Drosophila. In: Modulation of synaptic transmission and plasticity in nervous systems (Hertting G, Spatz H-C, eds), pp 351-368. Berlin: Springer.

Wu C-F (1996) Neuronal activity and neural plasticity in Drosophila. In: Basic neuroscience in invertebrates (Koike H, Kidokoro Y, Takahashi K, Kanaseki T, eds), pp 267-290. Tokyo: Japan Scientific Societies.

Wu C-F, Chen M-L (1995) Co-assembly of potassium channel subunits in Drosophila: the combinatorial hypothesis revisited. Chin J Physiol 38:131-138.

Wu C-F, Ganetzky B (1992) Neurogenetic studies of ion channels in Drosophila. In: Ion channels (Narahashi Y, ed), pp 261-314. New York: Plenum.

Wu C-F, Haugland F (1985) Voltage clamp analysis of membrane currents in larval muscle fibers of Drosophila: alteration of potassium currents in Shaker mutants. J Neurosci 5:2626-2640.

Wyman RJ, Thomas JB, Salkoff L, King DG (1984) The Drosophila giant fiber system. In: Neural mechanisms of startle behavior (Eaton RC, ed), pp 133-161. New York: Plenum.

Yao W-D, Wu C-F (1995) Drosophila Hyperkinetic mutations affecting K channel $\beta$ subunits alter firing pattern and $\mathrm{K}$ current properties in cultured "giant" neurons. Soc Neurosci Abstr 21:284.

Zhao M-L, Wu C-F (1997) Alterations in frequency coding and activity dependence of excitability in cultured neurons of Drosophila memory mutants. J Neurosci 17:2187-2199.

Zhao M-L, Sable EO, Iverson LE, Wu C-F (1995) Functional expression of Shaker $\mathrm{K}^{+}$channels in cultured Drosophila "giant" neurons derived from $S h$ cDNA transformants: distinct properties, distribution, and turnover. J Neurosci 15:1406-1418.

Zhong Y, Wu C-F (1991a) Altered synaptic plasticity in Drosophila memory mutants with a defective cyclic AMP cascade. Science 251:198-201.

Zhong Y, Wu C-F (1991b) Alteration of four identified $\mathrm{K}^{+}$currents in Drosophila muscle by mutations in eag. Science 252:1562-1564.

Zhong Y, Wu C-F (1993a) Differential modulation of potassium currents by cAMP and its long-term and short-term effects: dunce and rutabaga mutants of Drosophila. J Neurogenet 9:15-27.

Zhong Y, Wu C-F (1993b) Modulation of different $\mathrm{K}^{+}$currents in Drosophila: a hypothetical role for the Eag subunit in multimeric $\mathrm{K}^{+}$ channels. J Neurosci 13:4669-4679.

Zhong Y, Budnik V, Wu C-F (1992) Synaptic plasticity in Drosophila memory and hyperexcitable mutants: role of cAMP cascade. J Neurosci 12:644-651. 